\title{
Negação sentencial na diacronia do português: variação com estabilidade*
}

\author{
Verbal negation in diachrony of Portuguese: variation \\ with stability
}

\author{
Cristiane Namiuti \\ Unicamp
}

\begin{abstract}
Our goal is to prove the stability of negation in the Portuguese history. We propose get the fact that negation and verb always occur amalgamed in portuguese, and we also explain why negation was never been a context of XPs' interpolation, otherwise the others proclitic adverbals, but it was the greater interpolated element. We argue that these facts derive from an statute of clitic to negation. But, on the contary of the pronominal clitics, there wasn't any change about negation operator - 'não' - on the History of Portuguese. The analysis in the Distributed Morphology Theory foresees that the incorporation of $\mathrm{I}^{\circ}$ to $\Sigma$ - $\mathrm{Neg}^{\circ}$ is obligatory.
\end{abstract}

Keywords

Negation; Clitics; Gramatical change; Morphology.

\section{Resumo}

O objetivo deste trabalho foi provar a estabilidade do marcador de negação sentencial em toda a história do português versus a instabilidade dos pronomes clíticos, isto é, contrariamente ao que acontece com os clíticos pronominais, não houve mudança relacionada à palavra 'não' na diacronia do português. Nossa proposta captura o fato de o operador de negação 'não' ocorrer amalgamado 
ao verbo em toda a história do português. E ainda explica por que a negação, ao contrário dos demais operadores, jamais foi um elemento capaz de desencadear a interpolação de outros constituintes do sintagma verbal, mas foi o elemento que mais ocorreu interpolado entre o pronome clítico e o verbo no português antigo e clássico. Propusemos uma análise no quadro Minimalista da Morfologia Distribuída e argumentamos que a incorporação de $\mathrm{I}^{\circ}$ à $\Sigma-\mathrm{Neg}^{\circ}$ é obrigatória.

\section{Palavras-chave}

Negação sentencial; Clíticos; Mudança gramatical; Morfologia. 


\section{Introdução}

$\mathrm{O}$

presente artigo terá como pano de fundo o quadro teórico de Princípios e Parâmetros da Gramática Gerativa (cf. Chomsky, a partir de 1995). Nosso principal objetivo será trazer argumentos que sugerem uma estabilidade para o marcador de negação sentencial em toda a história do português.

De acordo com nossa hipótese, as variações encontradas no eixo temporal quanto à sintaxe da negação estão relacionadas com mudanças em outros domínios. Seguimos a idéia de Mioto (1992) para o português brasileiro de que o operador de negação ‘não’ é o núcleo de uma categoria acima de IP (Sintagma flexional, do inglês - Inflectional Phrase $)^{1}$ e que sofre um processo de incorporação ao verbo, explicando o fato de nenhum elemento, a não ser um clítico $\mathrm{X}^{\circ},{ }^{2}$ poder intervir entre a negação e o verbo em toda a história do português.

No entanto, ao contrário do que propõe Mioto, 'não' não é o núcleo de NegP (Sintagma de Negação, do inglês - Negative Phrase), mas de uma categoria funcional que porta conteúdos que não são necessariamente sintáticos, mas informacionais, comportando-se como um lugar de interface entre sintaxe e informação. Essa categoria foi designada de $\Sigma$ P por Laka (1990) e reinterpretada por Martins (1994). $\Sigma$ P instancia a polaridade sentencial de afirmação e negação (Af/Neg); em seu núcleo estão presentes traços associados com o verbo e com o complementador.

A relevância de $\Sigma$ está no fato de, com essa categoria, podermos capturar o comportamento semelhante exibido pelas operações de afirmação, negação e interrogação em relação a como expressam o seu conteúdo informacional (ver VALLDUVÍ, 1992).

A reflexão sobre os domínios oracionais negativos deverá, portanto, abordar questões que vão além da sintaxe, introduzindo dessa maneira um diálogo de interfaces.

Argumentaremos que a variação histórica encontrada nos domínios negativos comprova a existência de uma negação 'clítica' nas gramáticas do português. 
Entretanto, veremos que duas são as maneiras de construir o clítico negativo. A primeira é a maneira mais tradicional, via movimento da negação para $I^{\circ}$ - vide propostas de Pollock (1989), Belletti (1990), Martins (1994). Para tanto, a estrutura deve prever que NEGP esteja abaixo de IP. No entanto, esta não deverá ser a ordem da estrutura da frase em português. Como argumenta Mioto (1992), a estrutura que melhor dá conta dos processos que envolvem a negação nessa língua é aquela em que NegP domina IP, ou seja, com NegP acima de IP.

Sendo assim, a segunda maneira de pensar o clítico negativo foi proposta por Mioto (1992) e consiste em dizer que, no caso desse tipo de clítico, a cliticização não é feita via movimento do clítico, mas dos núcleos verbais para o clítico negativo, exatamente como acontece com a flexão verbal.

Portanto, para explicar a relação necessária e dependente do 'não' e do verbo, diversas análises consideram que essa inseparabilidade decorre do caráter clítico da negação.

Adotamos aqui a idéia do clítico negativo, mas acrescentamos que esse elemento tem também um caráter "flexional" e é a realização dos traços do núcleo funcional de polaridade $-\Sigma-\mathrm{Neg}^{\circ}$.

Para reforçar a proposta do clítico negativo, reinvocamos a idéia de Mioto (1992) de que a incorporação do 'não' ao verbo é obrigatória, e isso deriva do caráter clítico do operador de negação. Na sua proposta, ao contrário do que acontece com os clíticos pronominais, seria o complexo verbal que subiria para o clítico-negativo, pelo fato de $\mathrm{Neg}^{\circ}$ situar-se acima de IP. Essa derivação, porém, esbarra na questão do sujeito pré-verbal em português europeu moderno (doravante PE). De acordo com Costa (1999) (cf. também GALVES, 1996, entre outros) o sujeito pré-verbal no PE ocupa Spec/IP, e, estando a negação acima de IP, a ordem linear resultante não será compatível com a ordenação encontrada na língua - "sujeito-negação-verbo".

Proporemos uma alternativa no quadro minimalista da morfologia distribuída assumindo as reflexões de Martins (a partir de 1994) sobre a natureza e força dos traços de $\Sigma$ P. Dado que núcleos funcionais fortes precisam ser visíveis em PF (Forma Fonológica, do inglês, Phonological Form) ${ }^{3}$ (segundo a teoria dos traços), sendo $\sum-\mathrm{Neg}^{\circ} \mathrm{v}$-relacionado e com traços verbais fortes, a incorporação de $\mathrm{I}^{\circ}$ à $\sum-\mathrm{Neg}^{\circ}$ é obrigatória. Como o operador de negação em PE é uma espécie de clítico, $\Sigma-\mathrm{Neg}^{\circ}$ pode se afixar a $\mathrm{I}^{\circ}$ pela operação de abaixamento do núcleo $\Sigma-\mathrm{Neg}^{\circ}$ para a esquerda de $\mathrm{I}^{\circ}$. Esse processo deve ocorrer no componente morfológico antes da inserção vocabular e linearização. 
Quanto aos clíticos pronominais, eles obedecem a restrições de domínio morfo-fonológico e podem ser alinhados por deslocamento local após a inserção vocabular.

Portanto, a variação histórica na colocação dos clíticos pronominais nos domínios negativos deve derivar de duas constantes:

1. Do compartilhamento dos traços de núcleo e de clítico de NEG e CL quando estão em um mesmo domínio, a ordem ‘*neg-V-cl', com ênclise, não pode ser derivada por esse motivo.

2. Da posição do verboe da natureza do que antecede o complexo verbal a depender da gramática que subjaz as ordenações: Gramática arcaica, média ou moderna que vão derivar as ordens 'C-cl-(X)4-negV', (C)-X-clnegV e (C)-(X)-negclV.

Assim, iniciaremos nossa reflexão com a 'apresentação do problema' na seção 2. Seguiremos na seção 3 com a variação diacrônica nas orações negativas, observando o comportamento dos clíticos pronominais, dos pronomes fracos hy e en(de), e das outras palavras negativas nos domínios negativos comparado aos afirmativos na linha do tempo. Na seção 4 apresentaremos algumas propostas importantes sobre a sintaxe da negação sentencial comparando os domínios negativos e afirmativos, ponderando o caráter de clítico e de não clítico de 'não'. Na seção 5, traremos algumas considerações teóricas no quadro a Morfologia Distribuída para estruturar nossa proposta. Seguidamente, na seção 6, apresentaremos o licenciamento da categoria $\sum$ segundo nossa hipótese, para, finalmente, na seção 7 , fazermos as considerações finais.

\section{Apresentação do problema}

Como lembram Galves, Namiuti e Paixão de Sousa (2006, p.52), os estudos de mudança no quadro gerativo se fundamentam na investigação da variação diacrônica. A variação superficial da ordem é considerada uma abertura para se chegar a hipóteses sobre as gramáticas e sobre as mudanças gramaticais que ocorreram na língua em tempos remotos, uma vez que, na teoria, a ordem linear dos termos é reveladora da estrutura dos núcleos funcionais da frase abstrata.

A colocação dos clíticos pronominais é, portanto, um fator importante e bastante estudado na história da língua portuguesa.

Contudo, os trabalhos que investigam as mudanças dos padrões de colocação de clíticos na história do português não costumam considerar as 
sentenças negativas um ambiente interessante para se estudar a mudança gramatical que envolve a colocação dos clíticos. Na descrição e análise encontradas na literatura, a palavra 'não', assim como os operadores adverbiais e subordinativos, sempre desencadeou a próclise verbal obrigatória. Deste modo, como os advérbios que sempre provocaram a próclise verbal, a negação foi deixada em segundo plano nos estudos da colocação pronominal que envolvem mudança gramatical.

Entretanto, se olharmos atenciosamente para as sentenças negativas poderemos notar algumas valiosas pistas sobre a história gramatical da língua nos textos portugueses.

O marcador de negação sentencial 'não', apesar de condicionar invariavelmente a próclise verbal obrigatória nos domínios finitos, exibe um comportamento bastante diferente dos demais advérbios que desencadeiam a próclise obrigatória (ex: já, também, ainda, nunca) no sentido de sempre ter estado amalgamado ao verbo e jamais ter licenciado a interpolação de elementos entre o clítico e o verbo.

De acordo com Martins (1994), o fenômeno da interpolação entre o clítico e o verbo, comum no português antigo (doravante PA), só ocorre nos domínios de próclise categórica. Porém 'não', apesar de sempre ter sido um elemento proclisador, jamais foi capaz de desencadear a interpolação de um constituinte entre o clítico e o verbo como os demais advérbios proclisadores (a ordem 'neg-cl-X-V' nunca ocorre). No entanto, a interpolação da negação entre o clítico e o verbo ('cl-neg-V') no PA era preferida à ordem da próclise na qual o clítico está linearmente adjacente ao verbo ('neg-clV') em todos os ambientes de próclise categórica. Segundo Martins (1994), também Namiuti (2008), diferentemente da interpolação de outros constituintes, a interpolação do 'não' entre o clítico e o verbo pode ocorrer em contextos não-categóricos da próclise, em orações não dependentes 'neutras'5 e em infinitivas introduzidas pela preposição 'em' por exemplo. Namiuti (2008) chama a atenção para o fato de que a interpolação do 'não' nas orações não dependentes 'neutras' ocorre exatamente no mesmo período em que a próclise é dominante nesses ambientes nos domínios afirmativos.

Um segundo fato que comprova a diferença entre o 'não' e os demais advérbios é que nenhum outro elemento, a não ser um clítico, pode se colocar entre a negação e o verbo. Como atestam Muidine (2000) e Martins (2003a, 2003b e 2005) 'não' não influencia a colocação dos pronomes fracos 'hy' e 'en(de). Apesar de esses pronomes terem colocação pré-verbal nas orações 
raízes introduzidas por advérbios proclisadores, nunca ocorreram entre a negação e o verbo.

Essa estável inseparabilidade do 'não' e do 'verbo' em toda a história do português é no mínimo curiosa, e aguça a desconfiança de que o estatuto gramatical da negação não tenha sempre sido o mesmo.

Veremos que as soluções para dar conta da particular sintaxe dos clíticos nos domínios negativos giram em torno de se postular duas entradas lexicais diacrônicas para NEG, um morfema ou clítico verbal (a forma mais antiga) e um advérbio independente (forma inovadora em relação à antiga). De acordo com Martins (1994), essas duas formas teriam convivido no português em uma prolongada diglossia (desde o século 13), o português europeu moderno (doravante $\mathrm{PE}$ ) teria a segunda forma enquanto a primeira teria desaparecido da língua atual uma vez que considera que a ordem 'clnegV' é obsoleta no PE padrão. ${ }^{6}$

A hipótese que Martins $(1994 ; 1997)$ configura é que as gramáticas que admitem a interpolação da negação entre o pronome clítico e o verbo exibem um padrão clítico para "neg", uma forma fraca da negação ("morfema projetado do léxico" associado ao verbo), já as gramáticas que não admitem a interpolação de "não" tem a negação como um núcleo independente (gerado em $\sum-\mathrm{Neg}^{\circ}$ ) e a próclise é sempre derivada. Porém sendo a interpolação de neg quase categórica nos textos mais antigos, Martins conclui que a gramática em que o 'não' é um morfema verbal é a mais antiga. A gramática inovadora terá resultado da reanálise do morfema 'não' como núcleo lexical de S-Neg .

A seguir, na seção 3, veremos o comportamento da negação sentencial diante da variação na colocação de pronomes átonos e no uso dos indefinidos negativos.

\section{A variação diacrônica}

\subsection{Orações negativas com clíticos pronominais}

A ordem 'não pronome-clítico verbo' (doravante negclV) é obrigatória no português brasileiro $(\mathrm{PB})$ e preferencial no português europeu padrão (PE):

(1) "O Pedro confirmou que não me entregou o dinheiro"

Esta ordenação superficial sempre foi permitida no português. No entanto, como já mencionamos, a ordem mais comum no português arcaico, ou seja, 
aquela que mais se atestou no período anterior ao século 16 , foi a interpolação do marcador de negação sentencial entre o pronome clítico e o verbo 'Complementizador/ou outro subordinador-cl(X)negV' (doravante 'C-cl(X)negV) - com 'cl' contíguo à 'C'.

(2) "e certo que se lhe EIRei não mandára sucessor" (Couto-1548). ${ }^{7}$

Já no período "mediador" entre o português arcaico e o português atual (século 15 ao século 18) ${ }^{8}$ atestam-se as seguintes ordenações - '(C)-(X)-clnegV' - com o pronome clítico à esquerda de 'neg', podendo não estar contíguo à 'C' . Ainda nessa fase encontra-se a interpolação da negação entre o pronome oblíquo e o verbo em orações raízes neutras, contexto vedado à interpolação (mesmo da negação) em outras épocas.

(3) "que até o Prior dos Agostinhos, seu Confessor, o não pôde sofrer" (Couto-1548)

(4) "E, pelo ElRei Dom João o III querer casar, e êle não querer, lhe não deram satisfação de seus serviços ..." (Couto-1548)

\subsection{Orações negativas com 'hy' e 'en(de)'}

Como atesta Muidine (2000), diferentemente do que acontece com os clíticos 'acusativos' 'dativos' e 'se', a negação não influencia a colocação dos pronomes "hy" e "en(de)". Esses nunca podem ocorrer entre a negação e o verbo, ou seguem o complexo 'neg-V' ou o precedem. Tais pronomes têm colocação pós-verbal nas orações não dependentes "neutras" negativas - "negV-hylende'. Nos contextos de próclise obrigatória (orações subordinadas ou matrizes introduzidas por operador proclisador), o 'não' se encontra sempre adjacente ao verbo, o pronome fraco ou precede o complexo 'neg- $V$ ' - 'hylende$n e g-V$ ' - ou o segue - 'neg-V-hylen(de)'. Vejamos alguns exemplos do paradigma da colocação de ' $h y$ ' e 'ende' nos domínios negativos, repetidos de Muidine (2000):

(5) “... n e fizerõ ende n uqa áá Séé do portu treuudo nh enhúúm” (NO, 1285, p.43)" (MUIDINE, 2000, p. 26)

(6) “...e por dizimas que hy nõ pagei compridamente como deura. ..." (NO 1317, p.179)” (MUIDINE, 2000, p. 58) 
(7) "Que n eh uu cavalejro n e outro hom e nõ aia maladia en coutos dos Moesteiros n e das Ejgreias. se hi nõ ouuerem Quintáá ou herdade dauo ega (NO, séc. XII-XIV, p. 156)" (MUIDINE, 2000, p. 58)

(8) "E dem e pagem de fforo E penssom da dicta vinha E da dicta cassa E do dicto oliuall sseiçentos E quarenta Reaes brancos E quatro galinhas Em cada h uu ano ssaluo deste primeiro ano que nõm pagarom mais de duz etos Reaes $\mathrm{E}$ h uu par de galinhas porquanto hji nõ há noujdade no dicto oliuall ffazendo lhe pagam eto de todo (Lx, 1466, p.517)” (MUIDINE, 2000, p. 59)

(9) “(...) en represas (...) e deziã por sy e por o Conu ento a esse Juiz que nõ desse hj sentença que contra eles fosse $\mathrm{n} \sim \mathrm{e}$ sobre o sseu herdamento ca $n \sim u c a$ esta demãda fforõ $n \sim e$ seu procurador e cousa que hj fosse feyta ou procurada que lhis nõ enpeeçesse ca ó contradizia moy b e (NO, 1310, p.170)" (MUIDINE, 2000, p.58)

Vemos que a negação não influencia a posição dos pronomes deficientes ' $h y$ ' e 'ende'. Além disso, o fato de estes pronomes fracos jamais intervirem entre a negação e o verbo ('*...neg-hy| ende-V') corrobora fortemente a hipótese de 'não' ser uma espécie de clítico verbal.

Concluímos, pois, que as ordens encontradas só podem ser derivadas devido ao caráter nuclear de 'não' e dos pronomes acusativos e dativos em face ao caráter sintagmático de ' $h y$ ' e 'en(de)'.

Segundo Martins (2003a, p. 5), é conhecida e bem sustentada a generalização de que, nas línguas românicas, só elementos de natureza clítica $\left(\mathrm{X}^{\circ}\right)$ podem ocorrer entre o marcador de negação predicativa (pré-verbal) e o verbo.

\subsection{O marcador de negação sentencial e as outras palavras negativas (n-words)}

Tomaremos como base para a apresentação da variação histórica das palavras negativas o trabalho de Martins (2000).

A autora atesta que, nos romances antigos, os indefinidos negativos coocorriam com o marcador negativo aberto.

(10) "que nenh uu nõ scapou (Crônica Geral de Espanha de 1344.)" (cf. CINTRA, ed. 1954, p.107, apud MARTINS, 2000, p. 216, apêndice). 
Também era freqüente o uso de indefinidos negativos em contextos não negativos (conforme menciona MARTINS, 2000, p. 195). Esses contextos eram não-assertivos (não afirmativos) ou modais (questões, imperativos, condicionais, comparativos, o escopo do verbo modal, o escopo de expressões de proibição, construções genéricas e orações subjuntivas introduzidas por conectivos temporais como 'antes que').

(11) "E por decreto publico foi defeso que ninguém navegasse". (Cf. ALI, 1931, p. 199, apud MARTINS, 2000, p. 196) [significando 'e por um decreto público foi proibido que alguém navegasse']

Em estágio mais tardio (de acordo com Martins, século 15, no português) o marcador negativo passou a ser opcional:

(12) "Nenh uu nom mostrava que era famiinto" (Fernão Lopes, Crônica de D. João I. Freire, org 1997, p. 270, apud MARTINS, 2000, p. 194)

(13) "Nenh uu poderá seer emlegido a semelhante honra" (Fernão Lopes, Crônica de D. João I. Freire, org 1997, p.373, apud MARTINS, 2000, p.194)

Já os Romances Modernos, Martins (2000, p.196) afirma que nas línguas românicas modernas não existe uma que tenha o paradigma da obrigatoriedade da coocorrência do indefinido negativo pré-verbal com o marcador de negação sentencial e ainda a possibilidade de usar indefinidos negativos em contextos não negativos. Com certeza nãoé assim que se derivam as sentenças em português hoje.

No Português Europeu atual, indefinidos negativos pré-verbais não são permitidos coocorrerem com o marcador negativo.

(14) "Ninguém (*não) sabe o que se passa" (MARTINS, 2000, p.201)

OPE também não permite indefinidos negativos em contextos não negativos.

(15) “*Telefonou ninguém?” (MARTINS, 2000, p.201)

Um outro fato que contribui para o entendimento das diferenças no comportamento dos indefinidos negativos e da negação dos romances antigos $v s$ os modernos é que, nos primeiros, os indefinidos positivos podiam ocorrer em contextos negativos, Já nos segundos, eles perderam essa propriedade dos indefinidos positivos. (ver MARTINS, 2000, p. 211) 
Português Antigo

(16) "nom era algu $\sim \mathbf{u}$ ousado de lhe tall cousa dizer (Fernão Lopes, Crônica de D. João I. FREIRE (Org.). 1977, p. 6) (MARTINS, 2000, p. 219 - apêndice).

Português Moderno

(17) A Maria não comprou nenhum livro (MARTINS, 2000, p. 211)

(18) *A Maria não comprou algum livro (MARTINS, 2000, p. 211)

Martins (2000) considera que a variação encontrada no uso dos indefinidos negativos pode ser explicada pela motivação, em termos sintáticos, elaborada pela tipologia da distinção forte/fraca dos itens polares, já bem estabelecida na literatura semântica.

A autora pretende mostrar que, nos Romances, as palavras negativas evoluíram de itens com polaridade fraca para itens com polaridade forte. Isso é o que nos termos tradicionais, de acordo com Keniston (1937, p. 608, apud MARTINS, 2000, p.192), chamam de mudança de palavra "contextualmente negativa" (que adquire um 'sentido negativo' de uma palavra negativa em um contexto relevante) para intrinsecamente negativa. E argumenta ser necessário adotar uma teoria de traços que integra a noção de subespecificado para dar conta dos fenômenos de polaridade na sintaxe. ${ }^{9}$

Quanto à variação histórica no uso das formas sintáticas nas línguas românicas, Martins (2000) argumenta que tanto os indefinidos negativos quanto os positivos reduziram o seu aparato de variação subespecificada, ficando mais restritivos quanto aos contextos de licenciamento.

Considerando a hipótese de Martins (2000) da mudança nos indefinidos negativos que passam de palavras com um traço-neg a especificado no português antigo para traço-neg + especificado no português europeu, a dupla negação em sentenças, como nos exemplos (10) e (12), ou melhor, o fato de haver necessidade da presença do marcador de negação com o indefinido negativo pré-verbal nos romances antigos, mencionado e ilustrado por Martins, é indício da natureza operacional e de núcleo funcional do marcador de negação sentencial. Também o fato de o marcador de negação sentencial - 'não' - estar linearmente dependente do verbo desde os primeiros documentos escritos em português, como vimos nas subseções anteriores, leva-nos a dizer que a negação em português possui um caráter 'flexional', ou seja, 'não' está ligado fortemente à morfologia do verbo. 
Veremos, na seção 4 a seguir, outros argumentos que corroboram nossa hipótese. Mioto (1992), por exemplo, aponta para o fato de que a simples presença de uma palavra negativa não é suficiente para determinar que temos uma sentença negativa no português brasileiro.

(19) *João negou que a Maria viu nada.

O fato de (19) ser agramatical comprova que a negação sentencial no PB não se constrói lexicalmente, mas funcionalmente.

\section{A Negação Sentencial vs. Afirmação: fatos teóricos}

Diversos trabalhos sobre a negação sentencial tiveram pauta dentro do quadro gerativo no final da década de 80 e início dos anos 90 (citamos POLLOCK, 1989; IATRIDOU, 1990; CHOMSKY, 1989; LAKA, 1990; BELLETTI, 1990; OUHALLA, 1990; ZANUTTINI, 1991; MIOTO, 1992; entre muitos outros trabalhos).

Em grande parte das análises, uma sentença negativa é definida por meio de uma categoria funcional plena NegP que deve ter seu núcleo ou seu Spec preenchido por uma palavra negativa apropriada. Já o lugar em que essa categoria se encontra na estrutura da frase é bastante discutido na literatura do assunto (com muita polêmica).

Não é nosso objetivo resenhar com detalhes todas as propostas - outros trabalhos já fizeram isso com maestria, como Mioto (1992). Portanto, não entraremos nos detalhes de cada proposta para derivar a sintaxe da negação, mas cabe informar que todas admitem que IP corresponde, na verdade, a pelo menos duas categorias funcionais, AgrPe TP, respectivamente concordância e tempo. A relação de dominância entre essas categorias e NegP varia a depender da análise. $^{10}$

Mioto (1992), seguindo Belletti (1990), onde a ordem dos núcleos flexionais é a que AgrP domina TP, considera as três posições possíveis para NEGP:

(i) $\mathrm{CP}[\mathbf{N E G P}][$ AgrP $][\mathrm{TP}][\mathrm{VP}]$

(ii) $\mathrm{CP}[\mathrm{AgrP}][\mathbf{N E G P}][\mathrm{TP}][\mathrm{VP}]$

(iii) $\mathrm{CP}[$ AgrP $][\mathrm{TP}][\mathbf{N E G P}][\mathrm{VP}]$ 
De acordo com Mioto (1992), a estrutura que melhor descreve o comportamento da negação no Português Brasileiro é aquela em que NegP domina os núcleos INFL (Agr e T).

$\mathrm{O}$ autor argumenta que NegP é uma categoria do tipo [+I] por estar estreitamente relacionada com IP (AgrP e TP) e cumprir o papel de reverter o valor de verdade de uma sentença afirmativa.

Em sua análise NegPé gerado dominando outras categorias flexionais que podem ser reduzidas a IP. Para o autor, o fato de a negação sentencial fazer parte de um complexo indissolúvel "não+clítico+verbo" é o resultado do movimento obrigatório dos núcleos inferiores da flexão verbal para $\mathrm{Neg}^{\circ}$. A estrutura sintática proposta, portanto, é aquela em que NEGP domina IP:

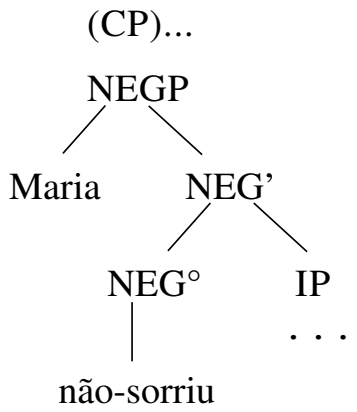

No entanto, a derivação da sentença negativa proposta por Mioto acarreta uma complicação para a teoria quando se assume que o caso nominativo é atribuído por I ${ }^{\circ}$ ao Spec de IP (pelo processo de concordância Spec-núcleo). ${ }^{11}$ Mioto resolve esse problema propondo que NegP tem disponível uma posição A de Spec, o que entra em choque com várias análises envolvendo o assunto.

Todavia, uma vez que se assume que NegPé uma categoria $+\mathbf{I}$, podemos considerar perfeitamente plausível que essa categoria possa ter uma posição $\mathbf{A}$ para a atribuição do caso nominativo.

Os principais argumentos em favor da estrutura em que NegP domina IP, e não outra, giram em torno dos seguintes fatos:

(A) Algumas línguas como o português (também o basco e o espanhol, de acordo com Laka (1990), possuem a capacidade de licenciar um IP nulo ${ }^{12}$ na oração coordenada. É importante lembrarmos aqui que a elipse deve ser licenciada por uma categoria funcional (cf. LOBECK, 1995, entre outros), o que comprova o caráter funcional da negação. 
(21) O Pedro agrediu o João, mas Paulo não.

(22) O Pedro não agrediu o João, e Paulo também não.

(B) A estrutura em que NEGP domina IP é a única que faculta captar a duplicidade da natureza clítica de "não". Isso porque, se NEGP estiver intercalado entre os nódulos de INFL, o comportamento de "não" no português não permitirá enquadrá-lo na classe de clíticos, pois pode reger um IP vazio:

(23) O Pedro agrediu o João, mas não o Paulo.

Já se NEGP domina IP, tanto o seu estatuto clítico, mediante a incorporação em $\mathrm{NEG}^{\circ}$ dos núcleos inferiores, quanto o seu estatuto de elemento que nãoé clítico, mediante a elipse do conjunto por ele dominado, podem ser diretamente derivados.

(C) Uma terceira vantagem envolve a posição pré-verbal dos advérbios negativos. Para uma língua como o PB, por exemplo, em que o verbo sobe para $\mathrm{I}^{\circ}$, a estruturação que tem IP como categoria funcional mais alta encontra sérias dificuldades para explicar a posição daqueles advérbios.

(24) O João nunca chora.

Resta-nos, porém, o problema de o sujeito estar em posição diferente nas sentenças afirmativas, não havendo paralelismo entre sentenças negativas e afirmativas quanto à posição do sujeito, pois, no primeiro caso, ocuparia o Spec de NegP; no segundo, o Spec de IP. Veremos que essa assimetria pode ser resolvida em análises como a de Martins (1994, 2000), inspirada em Laka (1990), Beletti (1997), entre outros, que propõem uma categoria funcional acima de IP responsável pelas operações de modificação tanto da negação quanto da afirmação. $\mathrm{Neg}^{\circ}$ seria o núcleo dessa categoria na sua instanciação negativa; sendo o marcador afirmativo nulo, o verbo é atraído para esse núcleo para checagem de traços, resultando que tanto nas orações negativas quanto nas afirmativas o sujeito pode ocupar o Spec dessa categoria.

Portanto, Martins (1994) também considera que a negação no português europeu está em um domínio acima de IP. Ela traz as observações de Laka (1990) para o inglês e para o basco, e de Chomsky (1957) para o inglês, de que existe um paralelismo entre construções negativas e construções afirmativas enfáticas. Em inglês tanto a negação quanto a afirmação enfática implicam a presença de 'do'. 
(25) Mary didn't leave

(26) Mary did leave [enfático, acento de intensidade sobre did]

Dada a similaridade de processos sintáticos envolvidos na negação e na afirmação enfática, Laka propõe que ambas são instanciações de uma categoria funcional $\Sigma$ ("Speech Act").

Para sua análise, Martins assume que $\Sigma \mathrm{P}$ faz parte da estrutura da frase e está presente não só nas afirmativas enfáticas, mas em todas as frases afirmativas. A idéia é que tal como uma proposição negativa implica uma operação de modificação por um marcador negativo, uma proposição afirmativa implica igualmente uma operação de modificação, sendo o operador afirmativo freqüentemente nulo, mas podendo, algumas vezes, ter realização lexical. Assim, de acordo com sua hipótese, $\Sigma^{\circ}$ é o núcleo de polaridade situado acima dos nódulos INFL e presente em todas as orações, ora instanciado como afirmação, ora como negação.

Nesta proposta não existe o problema da assimetria na posição do sujeito em orações negativas e afirmativas, pois a posição do sujeito no português europeu (PE) é sempre Spec de $\Sigma$ P nas orações não dependentes neutras. Nas orações raízes negativas, o marcador de negação sentencial 'não' ocupa o núcleo de $\Sigma$ P e o sujeito o Spec desse núcleo; nas orações raízes afirmativas, o verbo tem que subir para $\Sigma^{\circ}$ para checar os traços verbais fortes de $\Sigma^{\circ}$, portanto o sujeito pré-verbal das afirmativas também ocupa Spec de $\Sigma$ P.

Sobre os valores "forte" e "fraco" dos traços-Verbais de Neg eAf, Martins considera que não variam independentemente: em português, dado que Af tem traços- $\mathrm{V}$ fortes de acordo com a hipótese, Neg, se tem traços-V, terá igualmente traços- $\mathrm{V}$ fortes.

A esse respeito, duas hipóteses são apresentadas por Martins, sendo a segunda a mais interessante para a teoria:

$1^{\text {a }}$ - A negação não faz parte da morfologia verbal, portanto 'Neg' não terá traços-V, se exprime exclusivamente através do elemento lexical gerado em $\Sigma$-Neg, não.

$2^{a}$ - Se admitirmos que Neg, assim como Af, tem traços- $\mathrm{V}$, a negação se exprimirá através de dois marcadores negativos: o item lexical em Neg e um morfema abstrato associado ao verbo (o par, de polaridade oposta, do morfema afirmativo associado ao verbo quando Af é projetado). Sendo 
assim o verbo terá de se mover para $\Sigma$ para a verificação de traços também em frases negativas. Existe, porém, um fato relevante em relação às frases negativas: $\Sigma$, na sua instanciação negativa, tem conteúdo lexical. Esse fato pode ser interpretado de duas maneiras: ou 'não' é simplesmente a expressão fonética dos traços de $\sum$-Neg (a sua articulação); ou 'não' existe no léxico como item independente e é gerado como adjunto a $\Sigma$-Neg, verificando seus traços por confronto com traços contidos no núcleo a que se adjunge, isto é:

(27) $\left[\Sigma \mathrm{P}\left[\Sigma^{\circ} 1\right.\right.$ não $\left[\Sigma^{\circ} 2\right.$ (traços morfológicos) $\left.]\right] \ldots$

A esse respeito, é necessário salientar que núcleos funcionais com conteúdo lexical distinguem-se de núcleos funcionais sem conteúdo lexical pelo fato de seus traços serem convertidos em uma unidade tipo 'palavra'. Assim sendo, tais traços não se tornam ilegítimos em PF e nessas circunstâncias aplicase o princípio de economia (ADIE, seguindo CHOMSKY, 1993), fazendo com que o movimento do verbo para $\Sigma$-Neg ocorra só em LF. Em LF o verbo verifica os seus traços por confronto com os traços do item negativo que é o núcleo de $\Sigma \mathrm{P}$.

Se consideramos que o 'não' é um item lexical independente, quer 'não' quer o verbo terão que verificar seus traços por confronto aos traços de $\Sigma^{\circ} 2$ (representados apenas uma vez). Então o mecanismo de verificação deve se dar em duas partes: primeiro o item lexical negativo verifica seus traços por confronto com os traços de $\Sigma^{\circ} 2$ que são apagados concomitantemente. Mais tarde, o verbo move-se para $\Sigma-\mathrm{Neg}^{\circ}$ para verificar seus traços por confronto com os traços do item lexical negativo, e dado que traços morfológicos inerentes a itens lexicais não são vistos em PF o princípio Adie se aplica e o verbo se move para $\Sigma$ em LF.

Essa interpretação que Martins propõe para o mecanismo de verificação de traços implica que um elemento lexical possa ter seus traços morfológicos checados por confronto com os traços inerentes a um outro elemento lexical que realize ou seja parte de um núcleo funcional. Deste modo, uma categoria funcional com conteúdo lexical pode conter traços fortes sem que o movimento do verbo para a verificação de traços seja desencadeado na sintaxe visível.

Então, quer se admita que Neg não tem traços-V, quer se admita que Neg, assim como Af, tem traços- $\mathrm{V}$, em qualquer das hipóteses o verbo estará em AgrS quando a operação 'Spell-Out' ${ }^{13}$ se aplica, com o resultado de que os clíticos precedem o verbo em orações negativas. ${ }^{14}$ 
No entanto, 'não' foi durante um prolongado tempo (século 13 ao 19) produtivamente interpolado entre o clítico e o verbo.

Martins considera que a interpolação da negação é um fenômeno com características diferentes da interpolação de outros constituintes pelo fato de, entre os séculos 13 e 17, ocorrer com uma freqüência muito maior que a interpolação de outros constituintes e, a partir do século 17, a interpolação de 'não' continuar a se registrar, enquanto a interpolação de outros constituintes desaparece.

A perda da interpolação de outros constituintes no século 17 deve-se ao processo de reanálise que veda os clíticos ao acesso a $\Sigma$. E se a interpolação de 'não' continua a ocorrer, isso indica que a interpolação da negação não depende do movimento do clítico para $\Sigma$, ou seja, 'não' pode aparecer interpolado estando o clítico e o verbo em AgrS. A hipótese que Martins configura é que as gramáticas que admitem interpolação de 'não' este não é um núcleo autônomo, mas sim um morfema projetado do léxico associado ao verbo. Nas gramáticas que não admitem a interpolação de 'não', pelo contrário, este é o núcleo de $\Sigma \mathrm{P}$, sendo gerado em $\Sigma(=\mathrm{Neg})$.

Segundo a autora, as duas gramáticas coexistem desde o século 13, visto que a interpolação da negação não é obrigatória e a estrutura com o 'não' e o clítico adjacente ao verbo é atestada. No entanto, a gramática em que o 'não' é representado por um morfema verbal é claramente dominante no período medieval e clássico. Já o português europeu atual, segundo Martins, tem o morfema 'não' como núcleo (lexical) de $\Sigma$-Neg.
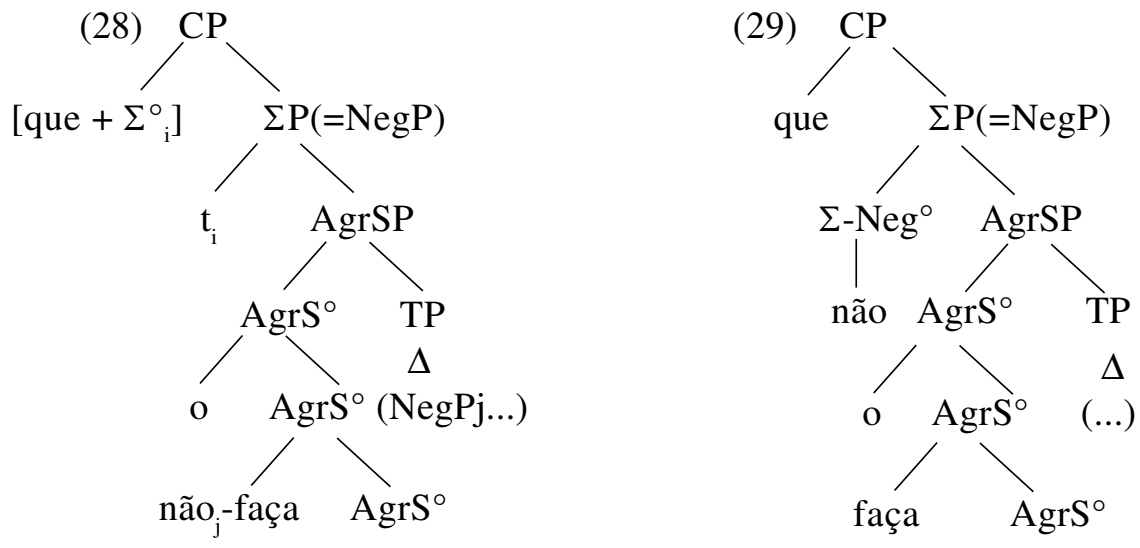
Essa análise se diferencia da análise de Mioto em dois aspectos principais:

(1) Em Mioto, $\mathrm{Neg}^{\circ}$ situa-se invariavelmente acima de $\mathrm{I}^{\circ}$ (o que equivale a $\operatorname{AgrS}^{\circ}$ na representação de Martins, 1994), mesmo quando clítico. Para ele, os núcleos flexionais é que se movem para o clítico negativo. Essa análise encontra paralelo no movimento do verbo para a flexão e não o contrário.

(2) Um segundo ponto, é que Mioto considera necessário manter a duplicidade do estatuto da negação no português, pois alguns fenômenos só são bem explicados se consideramos o estatuto clítico de $\mathrm{Neg}^{\circ}$; já outros, o estatuto de não-clítico. Como veremos a seguir.

\subsection{Sobre o caráter clítico de Neg}

Voltando à argumentação de Mioto (1992), o autor ressalva o fato de que, do ponto de vista fonológico [não-verbo], o 'não'é átono e tem grau de tonicidade de uma sílaba pré-tônica. Com base nesse ponto de vista 'não' poderia ser considerado um clítico. Além disso, a interação de 'não' com os clíticos pronominais permite reforçar a idéia de que ele é um clítico. Como aponta Mioto (1992), o clítico pronominal pode subir agregando-se a um verbo superior do qual ele não representa um papel temático, mas é impedido de fazê-lo se o 'não' estiver presente.

(30) ?A Maria te pode ajudar. (MIOTO, 1992, p.101)

(31) *A Maria te pode não ajudar. (MIOTO, 1992, p.101)

Costa (2004) também mostra que no PE a presença do operador de negação impede a subida do pronome clítico nas construções em que normalmente teríamos clitic climbing nos domínios afirmativos.

(32) “Eu devo não ver o Pedro". (COSTA, 2004, p. 52)

(33) “Eu devo não o ver”. (COSTA, 2004, p. 52)

(34) “*Eu devo-o não ver”. (COSTA, 2004, p. 52)

Mioto atribui a impossibilidade da subida do clítico causada pela negação ao fato de o 'não' e o clítico pronominal compartilharem traços de clítico, pois não basta compartilharem traços de núcleo para que 'Neg' bloqueie a subida do clítico pronominal. Atribuindo ao 'não' qualidades de clítico, é possível capturar sua capacidade de barrar a subida de elementos da mesma natureza. ${ }^{15}$ 
Do ponto de vista sintático, o caráter de clítico pode ser sustentado com base em sua incorporação ao verbo.

No entanto, a idéia que se tem defendido para os clíticos é que eles são elementos que se afixam ao seu hospedeiro via movimento. Portanto, o processo de cliticização, mesmo o de clíticos negativos, resulta do movimento do clítico.

Na proposta de Pollock (1989), também Belletti (1990), o complexo [não(cl)verbo] formado sobre a categoria funcional mais alta resulta de dois movimentos independentes:

1. O do complexo verbal que pula $\mathrm{Neg}^{\circ}$.

2. Depois o do clítico negativo.

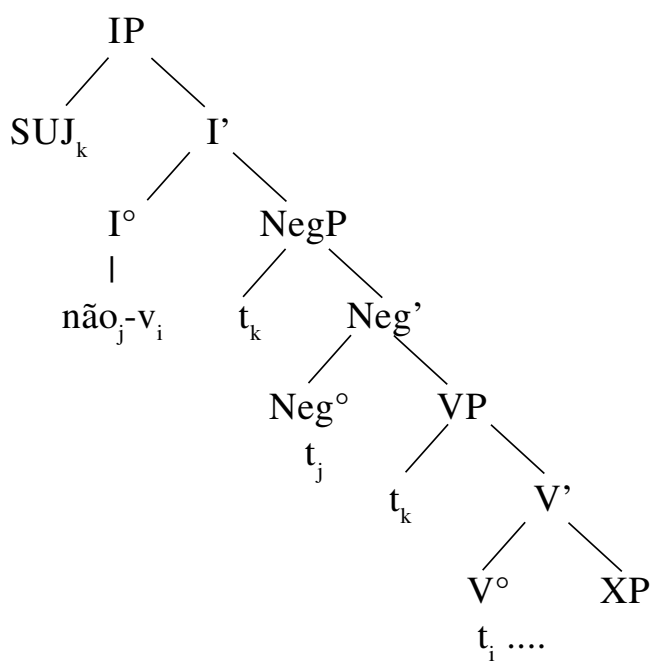

Nota-se que, para o processo de cliticização da negação ser derivado como o dos clíticos pronominais, ou seja, via movimento de $\mathrm{Neg}^{\circ}$, NEGP deverá situar-se abaixo de IP, ao contrário do que propõe Mioto.

A estrutura apresentada por Pollock encontra paralelo na estrutura que Martins (1994) traz para a versão de 'não' como um morfema verbal no PA.

$\mathrm{Na}$ análise de Mioto, NEGP é gerado acima das categorias flexionais (IP). Como o movimento de neg $^{\circ}$ para baixo desmontaria o sistema, o processo de cliticização não poderá ocorrer via movimento do clítico negativo. Para o autor, é o complexo verbal que sobe para o clítico negativo, o que não corresponde à descrição feita na literatura. $\mathrm{O}$ autor, porém, argumenta que o movimento do 
complexo verbal para $\mathrm{NEG}^{\circ}$ no processo de cliticização é possível em decorrência de NEGP encontrar-se acima de IP.

A 'inovação' de Mioto encontra paralelo no processo em que o verbo se move para que os afixos se amalgamem a ele, em vez de fazer os afixos descerem para o verbo; nessa idéia o 'não' e o 'verbo' formam um complexo resultante de um processo de incorporação.

De acordo com Baker (1988), a incorporação é obrigatória se um dos elementos for um afixo, pois existem restrições quanto à incorporação quando os núcleos adjacentes são núcleos lexicais plenos. Mioto traz como exemplo que corrobora a proposta de Baker uma sentença com o verbo 'ter' e o particípio em que há a possibilidade de intervenção de advérbios como 'sempre' entre os dois verbos do predicado.

(36) “A Maria tem sempre visitado os amigos”. (MIOTO, 1992, p.102) $)^{16}$

Entretanto, para o autor, a incorporação de 'não' ao verbo é obrigatória, apesar de considerar difícil construir uma idéia que encare o 'não' como afixo, recorrendo dessa maneira à idéia de que esse item é um clítico e é dessa propriedade que vem a capacidade de a negação sofrer um processo de incorporação, isto é, de atrair o complexo verbal formado abaixo dela. "O movimento do complexo $[\mathrm{V}+\mathrm{I}]$ para $\mathrm{Neg}^{\circ}$ decorre das qualidades de clítico e posiciona o complexo à direita de 'não', a posição canônica dos elementos que dão suporte ao clítico no PB.” (MIOTO, 1992, p.109).

A análise, portanto, traz embutida a restrição que opera sobre o processo de incorporação de núcleos - um núcleo só pode mover-se para uma posição nuclear lexicalmente preenchida quando pelo menos um dos núcleos envolvidos é afixo ou clítico.

Todavia, Mioto também julga necessário manter uma entrada lexical nãoclítica para $\mathrm{NEG}^{\circ}$ para explicar certas construções como um IP vazio na sentença coordenada e os casos em que ' $n \tilde{a} o$ ' vale como uma resposta negativa (inteira/completa).

(37) “O João agrediu o Pedro mas Paulo não.” (MIOTO, 1992, p. 103)

(38) “O João agrediu o Pedro? R: Não.” (MIOTO, 1992, p. 103)

No caso da resposta "Não" para a pergunta acima este 'não' instancia uma negação sentencial por dois motivos apontados por Mioto: 
(i) A resposta poderia ser 'Não agrediu'.

(ii) Para responder afirmativamente no $\mathrm{PB}$ (também no PE) poderia ser 'agrediu'. ${ }^{17}$

\subsection{A duplicidade de Neg}

Muitos estudos argumentam que a palavra 'não' não apresenta um comportamento uniforme nas línguas. Ora se comporta como $\mathrm{X}^{\circ}$, ora como $\mathrm{X}^{\mathrm{max}}$.

Zanuttini (1991), por exemplo, explora esta concepção de dois marcadores negativos, variáveis em relação ao seu estatuto e ao seu comportamento. Essa variação se encontra, segundo a autora, interlinguisticamente - o 'non' no italiano é um núcleo ao passo que 'nem' do Piemontês não é - e intralinguisticamente - o 'not' do inglês ora funciona como núcleo - sempre que pode ser substituído por ' $n$ ' $t$ '- ora como elemento de natureza adverbial, tipo $\mathrm{X}^{\max }$.

Já Dahl (1979) enquadra os marcadores negativos em três classes tipológicas em vista do seu comportamento:

- Primeiro, eles podem aparecer afixados ao verbo: no turco, o resultado disso é o complexo verbal 'verbo+Neg+tempo+concordância'. ${ }^{18}$

- Depois eles podem funcionar como auxiliares e, então, eles é que recebem afixos - como o árabe que tem o afixo de tempo amalgamado no marcador negativo.

- Além disso, eles podem ter caráter adverbial: no suíço alemão, por exemplo, o marcador negativo vem depois do verbo nas sentenças raízes e antes nas sentenças subordinadas.

Uma quarta situação, além das três descritas por Dahl, é a do clítico negativo (descrita nas seções anteriores), apesar de ela se enquadrar também na primeira situação descrita.

As explicações para as situações comportamentais descritas acima costumam colocar em causa o caráter nuclear vs. sintagmático do operador de negação sentencial.

No entanto, a divisão $\mathrm{X}^{\circ}$ e $\mathrm{X}^{\max }(\mathrm{XP})$ para dar conta da duplicidade da negação sentencial pode não ser a melhor maneira de explicar a negação em português.

Considerando outras categorias funcionais, o comportamento de 'não' é semelhante ao comportamento de um determinante $\left(\mathrm{D}^{\circ}\right)$. Ambos apresentam 
derivações aparentemente ambíguas: ora demonstrando uma dependência absoluta ao sintagma que encabeçam, ora podendo ser o único material que se resta de um apagamento, como no exemplo (37) de elipse do IP - 'agrediu'repetido abaixo em (39), e do exemplo (40) a seguir, com o NP(Noun Phrase - Sintagma Nominal) - 'posição' elidido:

(39) "O João agrediu o Pedro mas Paulo não. (MIOTO, 1992, p. 103)"

(40) "O sujeito pré-verbal do português médio ocupava uma posição equivalente à dos demais constituintes fronteados."

É importante notar que a presença do 'não' em (39) e do artigo em (40) é essencial para licenciar as elipses. Mas parece crucial a presença do acento tonal nesses casos. Nos casos de elipse de VP ou NP, a negação e o determinante, apesar de serem núcleos funcionais na sintaxe, passam a ser a cabeça lexical do sintagma fonológico.

Então, a 'negação', assim como o 'determinante', recebe o acento 'lexical' do sintagma fonológico que tem sua cabeça lexical elidida, pois, nesse caso, a fonologia entende que o núcleo funcional é a cabeça do sintagma fonológico. Dado que o núcleo lexical não é mais foneticamente realizado dentro do sintagma fonológico, há uma reinterpretação na atribuição do acento pela fonologia. ${ }^{19}$

Um fato que corrobora a hipótese da obrigatoriedade do acento nas construções de elipse no PB, por exemplo, é que nesses casos a forma foneticamente reduzida 'num' (para 'não') é agramatical:

(41) “*O João agrediu o Pedro mas Paulo num."

Sendo assim, tanto a negação quanto o determinante não podem ser prosodicamente deficientes nos casos de elipse, pois eles carregam o acento do sintagma fonológico.

Nos casos mais usuais, com o verbo ou nome explícitos, como 'O Pedro

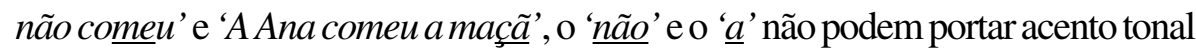

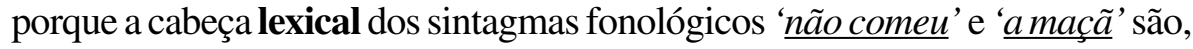

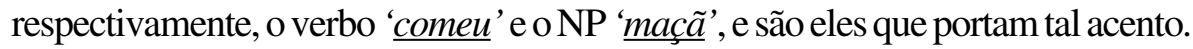

Quanto a essa proposta, temos indícios deste funcionamento sintático/ prosódico em textos históricos. Cyrino (1997) observa uma regularidade na acentuação proposta por João de Barros. ${ }^{20}$ Ao analisar o sintagma nominal, a autora chama a atenção para o fato de João de Barros acentuar os artigos (determinantes) 
nos sintagmas em que há elipse nominal. Nos casos em que o artigo é seguido do sintagma nominal completo o determinante não é acentuado:

(42) "Filho - Sam os cadernos da gramática da língua portuguesa... (DVV)"

(43) “Esses sam ôs que peço (DVV)” (NP elidido: cadernos)

É interessante observar que o autor usa esse recurso não para simplesmente marcar elementos fonologicamente acentuados, mas para uma distinção que tem uma explicação sintática. De acordo com Cyrino (1997, p.193), o autor acentua somente os determinantes que têm uma categoria vazia logo a segui-los.

Vale ressaltar que também os clíticos acusativos de $3^{\mathrm{a}}$ pessoa são acentuados por João de Barros, como mostra Cyrino (1997), fato que decorre da intuição deste estudioso de que a estrutura sintática dos sintagmas determinantes com elipse do NP é a mesma dos clíticos acusativos, conforme aponta Cyrino:

Os clíticos de terceira pessoa parecem ter um comportamento diferenciado dos clíticos de primeira e segunda pessoas. Uriagereka (1995) argumenta que clíticos de terceira pessoa seriam núcleos de sintagma determinantes ...
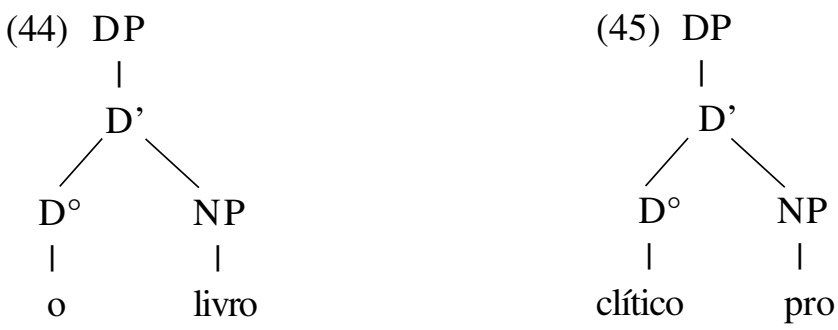

(46) Vi o livro

(47) Vi-o [ ]

Concluímos, então, que tanto o 'não' quanto os determinantes podem ter um comportamento aparentemente "ambíguo", pois ora se comportam como cabeça lexical, ora como categoria funcional.

Entretanto, a questão da ambigüidade da negação, vista na literatura lingüística, só faz sentido porque tomamos como parâmetro para clítico o 
processo de cliticização pronominal. ${ }^{21}$ Todavia, apesar de a negação, como o determinante, apresentar um comportamento semelhante ao dos pronomes clíticos (ser morfologicamente dependente de certas palavras), apresenta uma função de natureza diferente daquela reservada aos pronomes (argumentos do verbo). O marcador de negação é responsável por uma operação de modificação: 'não', ao instanciar a negação sentencial, inverte o valor de verdade do verbo. Já o determinante é responsável pela definitude dos sintagmas nominais.

De acordo com hipóteses como a de Lobeck (1995, 1997), entre outros, as construções de elipse são licenciadas por uma categoria funcional. Portanto, a capacidade de a negação licenciar VP nulo e receber o acento do material elidido nos leva a reforçar a idéia de que esta é uma categoria funcional.

Essa proposta vai ao encontro de Cyrino (1997, entre outros trabalhos) em que a ocorrência de elementos fonologicamente nulos deve ser licenciada por categorias funcionais. Os casos de elipse de VP, por exemplo, são licenciados segundo sua hipótese por um elemento em INFL ('flexão'). Em inglês, isso fica claro pela obrigatoriedade da realização do auxiliar (na sua instanciação negativa e afirmativa) nas construções com elipse do VP:22

(48) John saw his mother but Peter didn't ${ }_{\text {[see his mother] }}$

(49) John didn't see his mother but Peter did [see his mother]

(50) O João viu a sua mãe, mas o Paulo não ${ }_{\text {[viu sua mãe] }}^{23}$

(51) O João não viu a sua mãe, mas o Paulo ${ }_{[S}$ viu $_{j] \text { [ } t \text { j sua mãe] }}$.

Desse modo, somamos mais pontos para a hipótese de que o marcador de negação sentencial é a instanciação de um núcleo funcional - ligado a flexão verbal.

No entanto, não podemos defender a idéia de clítico para $\mathrm{Neg}^{\circ}$ tal qual ela tem sido implementada na maioria dos trabalhos sobre a negação, por conta das particularidades desse elemento reunidas neste trabalho. O que fica evidente é que o 'não' é um elemento nuclear, preso a uma certa morfologia sintagmática.

A fim de derivar esse fato, consideramos a idéia de Mioto de que 'não' é uma espécie de 'clítico' diferente dos clíticos pronominais que são clíticos que se movem.

No entanto, não gostaríamos de defender a duplicidade lexical de 'não' do mesmo modo que não se defende a duplicidade da natureza de ' $o$ ', ' $a$ ', ' $o s$ ', ' $a$ s' para derivar as construções que apresentam nomes lexicalmente realizados (ex: 
"Comprei o livro de física."), e as que apresentam a possibilidade da elipse nominal (ex: “O João comprou o - de matemática."), em ambos os casos tratam-se de 'determinantes', núcleo da categoria funcional DP (Determinant Phrase). ${ }^{24}$

A seguir traremos argumentos para defender uma unicidade para a negação. Veremos o comportamento de prefixos acentuados que constituem uma palavra prosódica independente, fazendo uma analogia com o operador de negação 'não'.

\subsection{A unicidade de Neg}

Lembremos que o 'não', apesar de sempre ter sido um desencadeador de próclise obrigatória em português, jamais foi capaz de desencadear a interpolação de XPs no português antigo e clássico, como os demais advérbios proclisadores.

Em análises como a de Martins (1994, 2005, entre outros trabalhos), em frases negativas com a ordem 'não-clítico-verbo', 'não' está contido em $\sum$, o verbo e o clítico em AgrS. Neste tipo de frase esperar-se ia que a interpolação de XPs fosse possível no Português Antigo, dado que os constituintes movidos por scrambling, de acordo com a proposta apresentada por Martins (2005), ocupam posições de Spec AgrS. No entanto, este não é um contexto em que se registrou a interpolação de XPs. Tal situação decorre, segundo Martins, da inviolabilidade de uma condição de adjacência entre 'não' e o 'verbo' - adjacência só interrompida por clíticos. Sob essa condição, a autora nada tem a dizer.

Ao somarmos o fato apontado por Mioto, também Costa (2004) para o PE, de que a presença do operador de negação impede a subida do pronome clítico nas construções em que normalmente teríamos clitic climbing nos domínios afirmativos, reforçamos a idéia do 'não' como uma espécie de 'clítico'. De acordo com Mioto (1992), tal situação deriva de a negação e o pronome compartilharem traços de clítico, pois não basta partilharem traços de núcleo para a negação bloquear a subida do clítico pronominal. ${ }^{25} \mathrm{Na}$ sua análise o 'não' e o 'verbo' formam um complexo resultante de um processo de incorporação.

Sabemos que a incorporação é obrigatória se um dos elementos for um afixo, pois existem restrições quanto à incorporação quando os núcleos adjacentes são núcleos lexicais plenos (BAKER, 1988). Evidência para isso é a possibilidade de intervenção de elementos entre os verbos de um predicado complexo. Repetimos o exemplo de Mioto com o advérbio ‘sempre' entre o verbo 'ter' e 
o particípio: “A Maria tem sempre visitado os amigos”. (MIOTO, 1992, p.102). “*Eu não sempre visito a Maria” não é uma construção possível em nenhum português.

Mioto, porém, considera difícil construir uma idéia que encare o 'não' como afixo, recorrendo dessa maneira à idéia de que esse item é um clítico e é dessa propriedade que vem a capacidade de a negação sofrer um processo de incorporação, isto é, de atrair o complexo verbal formado abaixo dela.

No entanto, a idéia de termos a negação como um afixo, mais exatamente prefixo no português, foi explorada recentemente por Santos (2005) em uma outra linha teórica.

Para nós, basta a idéia da necessidade da incorporação. Dar o nome de clítico, afixo ou partícula negativa vai depender da concepção do que seja cada um desses elementos.

Santos (2005) argumenta, dentro do quadro teórico funcionalista, a idéia do 'não' como prefixo no português brasileiro. Seus principais argumentos giram em torno da possibilidade de termos a palavra 'não' antecedendo imediatamente e negando um substantivo, ou um adjetivo ou um particípio. Estes não são casos de negação sentencial e Mioto (1992) assume, em uma nota, que a negação que antecede um elemento [+N] não pode ocupar $\mathrm{Neg}^{\circ}$, apesar de conservar o seu valor semântico, tampouco pode ser clítica. No entanto, acredito que caberia aqui a idéia da negação de categorias $[+\mathrm{N}]$ ser paralela ou derivar da negação sentencial.

A idéia do prefixo é interessante, porém fica difícil sustentá-la pela razão de o operador de negação 'não' licenciar uma categoria vazia, como nos casos de elipse. Todavia, Vigário (2003) mostra que prefixos acentuados podem licenciar a elipse do seu NP em estruturas de coordenação, por exemplo: "sílabas pré-tônicas e pós-tônicas" vs "sílabas pré e pós-tônicas” - a autora argumenta que o apagamento é possível porque prefixos como 'pré' e 'pós', 'macro' e 'micro', entre outros, têm o contorno entoacional de uma palavra prosódica. De acordo com Vigário (2003), palavras como 'macro-economista' têm as seguintes representações sintática, morfológica e prosódica: 


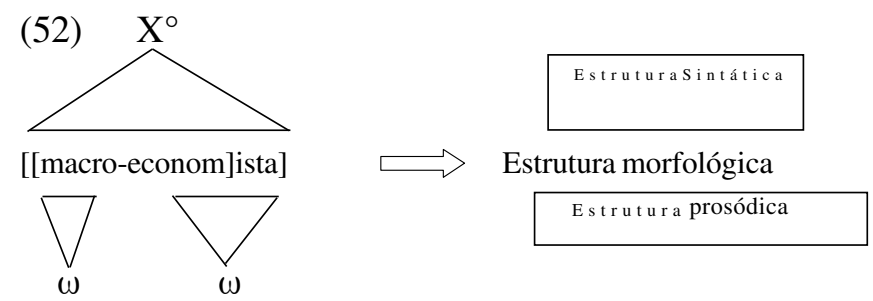

Em conclusão, apenas prosodicamente podemos identificar constituintes independentes, fato que leva Vigário a dizer que a explicação para derivar elipses como "macro e micro-economista" é de cunho prosódico, uma vez que somente uma análise prosódica nos permitirá manipular essas unidades independentemente.

Podíamos transferir essa idéia para a negação, já que 'não' é incorporado ao elemento negado (o verbo, no caso da negação sentencial), mas é provido de um acento que lhe dá certa independência prosódica (diferentemente dos pronomes clíticos do PE e PB).

Considerandoo fato de a negação ter um acento próprio, 'não' é prosodicamente independente do núcleo lexical de seu sintagma fonológico - o verbo. Portanto, o apagamento do núcleo lexical é possível quando recuperável no contexto. Neste ponto, podemos fazer a analogia com a proposta de Vigário (2005) para 'macroeconomista'

(53) O Paulo viu a Maria ontem, mas o João não (viu)

(54) $\mathrm{X}^{\circ}$

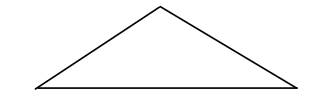

...[IP o João [ não + vitu ]<smiles>C1CC1</smiles>

$\omega$

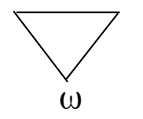

Estruturasintática

Estrutura morfológica

Estrutura prosódica

O mesmo raciocínio pode ser aplicado à resposta negativa mínima.

(55) O João viu a Maria? Não. 


\section{Considerações no quadro teórico da Morfologia Distribuída}

Somando os fatos apresentados nas seções anteriores, concluímos que: 1) A negação em português é a realização morfológica do núcleo de $\Sigma P$ na sua instanciação negativa, categoria funcional situada acima de IP mas do tipo +I. 2) Ao contrário do que propõem as análises tradicionais, só existiu um operador de negação em toda a história da escrita portuguesa: a negação em $\sum-\mathrm{Neg}^{\circ}$.

De acordo com Martins (1994, 1997, 2000, 2003a, 2003b, 2005), também Costa e Martins (2004), o núcleo funcional $\Sigma^{\circ}$ tem traços fortes em português e núcleos funcionais fortes requerem visibilidade ou suporte lexical. Por isso, tais núcleos são caracterizados por certas condições morfo-sintáticas.

Segundo a autora, uma categoria funcional forte pode licenciar constituintes nulos e, ainda, deve ser necessariamente parte da morfologia das palavras no componente morfológico da Gramática:

Departing from Chomsky (2000), I take the 'strength' property of a funtional category to be relevant in two ways: (i) strong funtional categories can license null constituints; (ii) strong funtional heads are necessarily part of spelled-out morphological words in the morphology component of grammar (cf. CHOMSKY, 1994, 1995, 2000; HALLE and MARANTZ, 1993; HARLEY and NOYER, 1999; EMBICK and NOYER, 2001). (MARTINS, 2005, p.178)

Portanto, núcleos funcionais fortes são necessariamente associados à morfologia e têm que ser visíveis em PF.

Esse propósito faz a predição de que a distinção entre visibilidade e invisibilidade está ligada à força forte e fraca dos traços do núcleo funcional. Sendo $\sum-\mathrm{Neg}^{\circ}$ forte em português, ele deverá ser visível em PF.

Segundo Martins (2005), os requerimentos para o núcleo funcional forte são satisfeitos concatenando (by merger) $\sum$ a um dos núcleos orientados pelos seus traços polares. Martins propõe que tais núcleos sejam $\mathrm{V}, \mathrm{C}$ e Neg.

No entanto, o MERGER pode ocorrer no componente sintático ou póssintático-componente morfológico.

Portanto, os núcleos funcionais fortes podem ser licenciados de três maneiras: ${ }^{26}$ 
(1) lexicalizado por 'merger' sintático

(2) por movimento nuclear ou sintagmático

(3) por 'merger' morfológico

Seguindo a proposta da Morfologia Distribuída (MD), merger não representa a concatenação de dois elementos, mas a afixação $^{27}$ de um núcleo $\mathrm{X}$ a um núcleo Y. Além disso, enquanto merger na sintaxe se dá "de baixo para cima", ou seja, do constituinte mais simples vai se formando o mais complexo, na MD a operação se dá de duas maneiras:

1) por abaixamento antes da inserção vocabular, e,

2) por deslocamento local, requerimento de adjacência linear que caracteriza merger na morfologia após o processo de linearização e inserção vocabular.

Após a computação sintática, no primeiro estágio da morfologia, antes da inserção vocabular, temos o abaixamento de um núcleo $\mathrm{X}^{\circ}$ para um núcleo $\mathrm{Y}^{\mathrm{o}}$ :

(56) $\left[\mathrm{XP}\left[\mathrm{X}^{\mathrm{o}}\right] \ldots\left[\mathrm{YP} \ldots\left[\mathrm{Y}^{\mathrm{o}}\right] \ldots ..\right]\right]-\left[\mathrm{XP} \ldots . .\left[\mathrm{YP} \ldots\left[\mathrm{Y}^{\mathrm{o}} \mathrm{Y}^{\mathrm{o}}+\mathrm{X}^{\mathrm{o}}\right] \ldots.\right]\right]$

(57) *[TP Mary $\left[\mathrm{T}^{\circ}\right.$ did] [IP loudly $\left[\mathrm{I}^{\circ}\right.$ play $]$ the trumpet $\left.]\right]-$ [TP Mary [ $\mathrm{tj}]$ [IP loudly $\left[\mathrm{I}^{\circ}+\mathrm{T}^{\circ}\right.$ play-edj] the trumpet]]

O processo de deslocamento local segue a hipótese de linearização tardia: os elementos da estrutura sintática são linearizados durante o processo de inserção vocabular de acordo com a periferalidade dentro de um constituinte. Esta operação de movimento é sensível às matrizes fonológicas dos itens vocabulares (vocabulary sensitive) e envolve somente itens linearmente adjacentes, tendo que ser mantidas as condições de adjacência.

(i) $\quad \alpha^{*} \beta=\alpha$ deve preceder linearmente $\beta$ e ser adjacente a $\beta$

(ii) $\quad \beta^{*} \alpha=\beta$ deve preceder linearmente $\alpha$ e ser adjacente a $\alpha$

(58) $\left[\mathrm{X}^{*}\left[\mathrm{Z}^{*} \mathrm{Y}\right]\right]-\sigma\left[\left[\left[\mathrm{Z}^{\circ} \mathrm{Z}+\mathrm{X}\right]^{*} \mathrm{Y}\right]\right]$

Em $\varpi \mathrm{X}$ precede imediatamente $\left[\mathrm{Z}^{*} \mathrm{Y}\right]$ e $\mathrm{Z}$ precede imediatamente $\mathrm{Y}$. Tomemos s como resultado da aplicação de deslocamento local a $\varpi$. Todas as condições de adjacência estabelecidas em $\varpi$ são mantidas em $\sigma$, o que garante a legitimidade da operação.

São bons exemplos para esse movimento as construções com clíticos em português. 
De acordo com Embick e Noyer (2001), a ordem linear não é uma propriedade da representação sintática, mas é imposta em PF em virtude do requerimento de que a fala é instanciada em um tempo. Então, é natural assumir que a ordem linear é imposta no ponto da derivação em que a informação fonológica é inserida. Sendo assim, a MD vai postular The Late Linearization Hipotesis (hipótese de linearização tardia). Os elementos de um marcador de sintagma ou frase são linearizados pós-sintaticamente na Inserção Vocabular e, depois da linearização, o Merger "Deslocamento local" pode manipular apenas elementos adjacentes linearmente, não importando a hierarquia, mas sim a precedência e adjacência linear. Os elementos passíveis de deslocamento local são os que são vocabulary sensitive, por exemplo, os clíticos pronominais.

De acordo com a proposta de Galves e Sândalo (2004), seguindo a generalização de Kayne (1991), ${ }^{28}$ a colocação de clíticos no português europeu é o resultado da interação morfológica edgmost (CL, L, I' $)^{29}$ dominada pela restrição Non-Initial (CL, $\left.1^{\circ} \mathrm{X}^{\prime}\right){ }^{30 / 31}$ As autoras se baseiam no ponto de vista de Anderson (2000) de que os clíticos estão sujeitos a regras de formação de palavras como um afixo. A análise se enquadra dentro da Teoria da Otimalidade (OT).

Essa proposta se mostrou empiricamente adequada uma vez que pode explicar, sem exceção, todas as situações que envolvem os clíticos pronominais e ainda capta a intuição de que eles são elementos regidos por condições de interfaces (sintaxe/morfologia/fonologia).

Transportamos para o quadro da MD a proposta de Galves e Sândalo (2004) de que o clítico em PE deve se alinhar à esquerda de I'. Nas frases não dependentes neutras, como (59), I' é o primeiro X' da oração, e, uma vez que a ênclise em PE é vocabulary sensitive, a restrição morfo/fonológica 'Non Initial' se aplica e a ênclise é derivada no componente morfológico através da operação de deslocamento local que deverá manter as condições de adjacência do clítico. Portanto, o pronome deve continuar adjacente a I' e I' à I' .

Na derivação da ênclise em (60) essas condições não se mantêm: uma vez que o clítico se desloca para fora do complexo $\mathrm{I}^{\circ}+\mathrm{V}^{\circ}$ ele deixa de estar adjacente a I' e passa a estar adjacente apenas à $\mathrm{I}^{\circ}$. Deste modo, o clítico deve se deslocar para dentro do núcleo verbal, incorporando-se à palavra, então a operação de Merger deslocamento local para derivar a ênclise não violaria as condições de adjacência do clítico, como podemos constatar em (61). 
(59) *[IP A Maria lhe I' $\left[\mathrm{V}^{\circ}\right.$ deu $\left.\operatorname{Infl}{ }^{\circ}\right]$ um presente ]

(60) *[IP A Maria ti I' $\left[\mathrm{V}^{\circ}\right.$ deu $\left.\operatorname{Infl}{ }^{\circ}\right]$ lhei um presente]

(61) [IP A Maria ti I' [ $\mathrm{V}^{\circ}$ deu- lhei Infl ${ }^{\circ}$ ] um presente] $\leftarrow$

Podemos concluir, portanto, que os clíticos em PE movem-se na sintaxe para a esquerda do verbo, derivando a próclise, e é somente na inserção vocabular que a ênclise é derivada por deslocamento local, a depender da natureza sintática do elemento que antecede o verbo. Deslocamento local só será aplicado quando I' for o primeiro X' da oração. No entanto, esta não pretende ser uma proposta exaustiva visto que procuramos não entrar nos detalhes da estrutura sintática das sentenças do PE, preferimos dá-la simplificada com o intuito de exemplificar a operação.

Passemos agora para a questão da negação e às generalizações da morfologia de $\Sigma$.

\section{Licenciando $\Sigma$}

Como já mencionamos, o núcleo funcional $\Sigma$, que carrega valores polares como a negação e afirmação, é forte em Português. No entanto, Costa (1999, 2004, entre outros trabalhos) mostra que o verbo não se move além de "T" (T=I), ou seja não chega ao $\Sigma$ P. Então propõe que $\Sigma^{\circ}$ é licenciado por merger morfológico com "V+T". Na sua análise, se $\Sigma^{\circ}$ contiver conteúdo lexical, como a negação, ou for licenciado independentemente por merger com $\mathrm{C}^{\circ}$ lexicalizado (nas orações dependentes), então o 'merger' morfológico de $\Sigma$ com 'V+T' não será necessário.

Todavia, a análise de que quando $\Sigma$ é lexicalizado pela negação não há 'merger' com o verbo deveria predizer que a ordem dos constituintes poderia ser 'neg-Sujeito-verbo' e ainda que nas fases mais antigas a negação poderia contextualizar a interpolação de outros constituintes como o sujeito. Entretanto sabemos que a ordem nas sentenças negativas sempre foi 'Sujeito-negaçãoverbo' e que a interpolação nunca pode ser desencadeada pela negação. Para capturar esses fatos, precisa-se lançar mão de uma estipulação de que o Spec de TP (IP) não é ativo nas sentenças negativas, o que compromete a 'elegância' da teoria.

Partindo da conclusão a que nos levaram as sessões anteriores que apontaram que 'não' é uma espécie de clítico verbal, a instanciação morfológica do núcleo de $\Sigma-\mathrm{Neg}^{\circ}$ (estando esta categoria funcional acima de IP na estrutura da oração), duas são as maneiras de derivar o complexo 'neg-V': 
1. Por concatenação (merger) de $\mathrm{I}^{\circ}$ a $\sum-\mathrm{Neg}^{\circ}$ na sintaxe, exatamente como propõe Mioto (1992), com a diferença de que temos $\Sigma$-NegPem vez de NegP, e de que também nos domínios afirmativos $\mathrm{I}^{\circ}$ se funde $\mathrm{a} \Sigma-\mathrm{Af}^{\circ}$, dado que os valores forte/ fraco de $\Sigma$ não variam independentemente, como propõe Martins (1994).

No entanto, isso levaria a dizer que o sujeito pré-verbal no PE deva ocupar o Spec de $\Sigma$ P, o que vai contra diversas análises envolvendo o assunto, como Costa (1998, 1999), Costa e Duarte (2002), Galves (1992, 1996, 2001, 2003), Galves e Paixão de Sousa (2005) entre outros, que argumentam fortemente que a posição do sujeito pré-verbal em PEé, simplificando as análises, Spec IP (TP).

De acordo com Costa (1998), o sujeito pré-verbal não pode ocupar uma posição de adjunção à esquerda, como os tópicos, ${ }^{32}$ ao contrário do que propõe Barbosa (1995, 2000), ${ }^{33}$ e também não pode ocupar uma posição de fronteamento como Spec de $\Sigma \mathrm{P}$ visto que é provável que o preenchimento dessa posição desencadeie a próclise ${ }^{34} \mathrm{e}$ as orações não dependentes ' $\mathrm{SV}$ ' são ambientes categóricos de ênclise no PE.

Galves e Paixão de Sousa (2005) reforçam a idéia de que o Sujeito ocupa Spec de IP no PE ao mostrar que no período gramatical anterior (o qual foi chamado, seguindo a tradição, de Português Clássico - PC) a ordem 'XSVcl' era extremamente rara e só se tornou frequiente a partir do século 18. Segundo as autoras, nos textos do período clássico, quando mais de um constituinte antecede o verbo, a próclise é normalmente derivada, a ordem padrão seria 'XSclV'. No entanto, na sua análise, o sujeito no PC podia ocupar uma posição de fronteamento interna à estrutura da oração (Spec de $\Sigma$ P por exemplo), o que explicava a próclise nesse ambiente. Já a ênclise seria o efeito de V1 nessa fase. Galves (2002) e Galves e Paixão de Sousa (2005) argumentam que nas orações V2 com ênclise, como 'SVcl', o constituinte pré-verbal está fora do domínio da oração. Portanto, a proposta de Barbosa para o PE cai bem para o PC. A mudança estaria na reanálise da posição pré-verbal do sujeito com ênclise que deixa de ser externo e passa a ser interno. Como o preenchimento do Spec de $\Sigma P$ não é compatível com a ênclise, a posição do sujeito pré-verbal fica sendo Spec/IP. Consequentemente, 'SV' deixa de ser um ambiente de próclise.

2. A segunda maneira de resolver a questão, mantendo o sujeito em Spec/IP, é resolvê-la no componente morfológico: dado que $\Sigma-\mathrm{Neg}^{\circ}$ tem traços verbais fortes e que o operador de negação em português é uma espécie de clítico, $\Sigma-\mathrm{Neg}^{\circ}$ pode se afixar a $\mathrm{I}^{\circ}$ pela operação de abaixamento do núcleo $\Sigma-\mathrm{Neg}^{\circ}$ 
para a esquerda de $\mathrm{I}^{0}{ }^{35}$ Esse processo deve ocorrer no componente morfológico antes da inserção vocabular e linearização. Se houver um complemento clítico, o pronome se moverá para dentro do complexo [não ${ }_{-\Sigma-\mathrm{Neg}^{\circ}}$ verbo $\mathrm{I}^{\circ}$ ] na inserção vocabular por deslocamento local, mantendo suas condições de adjacência e resultando no complexo 'negação-clítico-verbo' ${ }^{35}$

Propomos que no PE, se $\Sigma$-Af é projetado e nada mais (nenhum $\mathrm{C}$ ou operador em Spec de $\sum$-AfP), a operação de merger $\sum-\mathrm{Af}^{\circ}+\mathrm{I}^{\circ}$ se aplica.

(62) $\left[\Sigma \mathrm{P}\right.$ ti [IP O Paulo I' $\left[\Sigma-\mathrm{Afi}^{\circ}+\mathrm{I}^{\circ} \mathrm{viu}\right]$ a Ana ontem no parque $\left.]\right]$

Nesta configuração I' é o primeiro X' da oração, portanto, assumindo a intuição de Galves e Sândalo (2004) para a colocação dos clíticos pronominais, quando o argumento interno do verbo for clítico, a operação de deslocamento local se aplica:

(63) $*\left[\Sigma \mathrm{P} t_{\mathrm{i}}\left[\mathrm{IP}\right.\right.$ O Paulo me I' $\left[\Sigma-\mathrm{Afi}^{\circ}+\mathrm{I}^{\circ}\right.$ viu $]$ ontem no parque $\left.]\right] \rightarrow$ [ $\Sigma \mathrm{P} \mathrm{t}_{\mathrm{i}}$ [IP O Paulo tc I' $\left[\Sigma-\mathrm{Afi}^{\circ}+\mathrm{I}^{\circ}\right.$ viu-mec] ontem no parque]]

O mesmo raciocínio podemos fazer para os domínios negativos, porém ponderando o fato de o operador de negação também ser clítico.

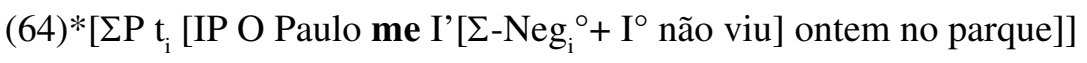

$(65) *\left[\Sigma \mathrm{P} \mathrm{t}_{\mathrm{i}}\left[\mathrm{IP}\right.\right.$ O Paulo $\mathrm{t}_{\mathrm{c}} \mathrm{I}^{\prime}\left[\Sigma-\mathrm{Neg}_{\mathrm{i}}{ }^{\circ}+\mathrm{I}^{\circ}\right.$ não viu-me $]$ ontem no parque $\left.]\right]$

(66) [ $\Sigma \mathrm{P} \mathrm{t}_{\mathrm{i}}$ [IP O Paulo $\mathrm{t}_{\mathrm{c}} \mathrm{I}^{\prime}\left[\Sigma-\mathrm{Neg}_{\mathrm{i}}{ }^{\circ}+\mathrm{I}^{\circ}\right.$ não mec viu] ontem no parque]]

O pronome clítico não pode ficar alinhado à esquerda de I', como em (64), por este ainda ser o primeiro X' da oração. Porém, como 'não' é clítico, a operação de deslocamento moverá o clítico pronominal para dentro do complexo deixandoo adjacente ao 'não'. A ordem em (66) é a ordem gramatical, sua derivação pode ser explicada (ou motivada) pelos seguintes fatos já mencionados neste texto: 1) o fato de os clíticos ocorrerem adjacentes (impedindo 'não-verbo-clítico'); e 2) o fato de o pronome não poder portar o acento inicial de palavra fonológica do PE (impedindo 'clítico-não-verbo').

Essa proposta captura o paralelismo nas operações de 'negação' e 'afirmação'. $\sum$ deve se concatenar a I ${ }^{\circ}$ mesmo quando é preenchido por 'neg' e isso deriva do caráter clítico do operador 'não' que obriga a incorporação do 'não' ao ‘verbo', como propõe Mioto. Como resultado, conseguimos a assimetria na posição do sujeito em ambos os domínios, além de poder capturar a diferença 
prosódica e morfológica da ênclise $v s$ a próclise (FROTA, 1994; BARBOSA, 2000; GALVES; DOBROVIE-SORIN, 2000, VIGÁRIO, 2003) e o fato de os pronomes enclíticos estarem mais intrinsecamente (tighter) relacionados com seu hospedeiro que os proclíticos (BENINCÁ e CINQUE, 1993).

A hipótese também pode explicar a derivação da elipse e as respostas mínimas a interrogativas totais 'sim'l'não' sem postular uma outra categoria para a negação. Isso porque, sendo o núcleo funcional $\sum$ forte em português, a elipse de IP é lícita e dela se deriva a resposta negativa mínima. Nesses casos a negação em $\Sigma-\mathrm{Neg}^{\circ}$ porta um acento lexical.

\section{Considerações finais}

Nosso objetivo principal foi reunir todo um conhecimento sobre a negação sentencial a fim de entender as derivações sintáticas nos domínios negativos e a natureza do marcador de negação 'não' na história da escrita portuguesa descrita na literatura lingüística.

Nesta empreita, mostramos, com a variação histórica encontrada nos domínios negativos, que a existência de uma negação 'clítica' nas gramáticas do português é necessária. Entretanto, vimos que duas são as maneiras de construir o clítico negativo.

A maneira tradicional é via movimento de $\mathrm{Neg}^{\circ}$ para $\mathrm{I}^{\circ}$, vide propostas de Pollock (1989), Belletti (1990), Martins (1994). Para tanto, a estrutura deve prever que NEGPesteja abaixo de IP. No entanto, esta não deverá ser a ordem da estrutura da frase em português. Como argumenta Mioto (1992), a estrutura que melhor dá conta dos processos que envolvem a negação é a que NegP domina IP.

A segunda maneira de pensar o clítico negativo é dizer que, no caso deste tipo de clítico, a cliticização não é feita via movimento do clítico, mas dos núcleos verbais para o clítico negativo, exatamente como acontece com a flexão verbal.

Em contrapartida, vimos que as operações de negação e afirmação têm comportamentos paralelos, e a sintaxe deriva as operações de negação e afirmação por meio de uma categoria funcional presente na estrutura da oração e que faz interface com o conteúdo informacional. Essa categoria foi designada $\Sigma$ P por Laka (1990) e Martins (1994). No entanto, apesar das propostas de Martins e Laka concordarem com a necessidade dessa negação que chamamos "clítica" em algumas línguas, o processo de cliticização da negação é paralelo ao dos clíticos pronominais, prevendo então uma categoria NEGP abaixo de IP 
além da categoria $\sum$-negP. Portanto, joga com duas negações, sendo a negação de $\sum$-negP não-clítica.

Trouxemos várias evidências de que o marcador de negação sentencial 'não' é um morfema estreitamente associado ao verbo. Em resumo, vimos que nenhum elemento, a não ser um clítico $\mathrm{X}^{\circ}$, pode intervir entre a negação e o verbo em toda a história do português, e ainda, que a presença do 'não' é essencial para licenciar o contexto negativo - no PA os indefinidos negativos precisavam coocorrer com o marcador de negação para expressar uma idéia negativa, uma vez que não eram inerentemente negativos. Também que a negação, ao contrário dos demais operadores, jamais foi um elemento capaz de desencadear a interpolação de outros constituintes do sintagma verbal, mas foi o elemento que mais ocorreu interpolado entre o pronome clítico e o verbo.

Para explicar essa relação necessária e dependente do 'não' e do verbo, diversas análises consideram que essa inseparabilidade decorre do caráter clítico da negação. Adotamos aqui parte da idéia do clítico negativo, ${ }^{36}$ mas acrescentamos que esse elemento tem também um caráter "flexional" e é a realização dos traços do núcleo funcional de polaridade $-\Sigma-\mathrm{Neg}^{\circ}$.

Para reforçar a proposta do clítico negativo, reinvocamos a idéia de Mioto (1992) de que a incorporação de 'não' ao verbo é obrigatória, e isso deriva do caráter clítico de 'não'. Vimos que, na sua proposta, ao contrário do que acontece com os clíticos pronominais, é o complexo verbal que sobe para o clítico-negativo, pelo fato de $\mathrm{Neg}^{\circ}$ situar-se acima de IP. Porém, essa derivação esbarra na questão do sujeito pré-verbal em PE. A análise tradicional prevê que o sujeito préverbal ocupa Spec/IP.

Propusemos uma alternativa no Quadro Minimalista da Morfologia Distribuída. Dado que $\boldsymbol{\Sigma}-\mathbf{N e g}^{\circ}$ tem traços verbais fortes, e, que núcleos funcionais fortes precisam ser visíveis em $\mathrm{PF}$, segundo a teoria dos traços, sendo $\Sigma$-Neg ${ }^{\circ}$ v-relacionado e com traços verbais fortes, a incorporação de $\mathrm{I}^{\circ}$ à $\Sigma$-Neg ${ }^{\circ}$ é obrigatória. Como o operador de negação em português é uma espécie de clítico, $\Sigma$-Neg ${ }^{\circ}$ deve se afixar a $I^{\circ}$ pela operação de abaixamento do núcleo $\Sigma-\mathrm{Neg}^{\circ}$ para a esquerda de $\mathrm{I}^{\circ}$. Esse processo deve ocorrer no componente morfológico antes da inserção vocabular e linearização.

Quanto aos clíticos pronominais, eles obedecem a restrições de domínio morfo-fonológico e podem ser alinhados por deslocamento local após a inserção vocabular. 
Portanto, a variação histórica na colocação dos clíticos pronominais nos domínios negativos deve derivar de duas constantes:

1) do compartilhamento dos traços de núcleo e de clítico de NEG e CL quando estão em um mesmo domínio, a ordem ‘*neg-V-cl', com ênclise, não pode ser derivada por esse motivo;

2) do contexto armado pelo que antecede o complexo a depender da gramática que subjaz as ordenações: gramáticas arcaica, média ou moderna que vão derivar as ordens 'C-cl-(X)-negV', (C)-X-clnegV e (C)-(X)-negclV, conforme a hipótese sobre as três etapas gramaticais apresentada em Namiuti (2008).

Deste modo, sustentamos a hipótese de que o marcador de negação 'não' é invariável em toda a história do português, ou seja, não sofre nenhuma mudança diacrônica quanto a sua natureza de núcleo funcional associado à morfologia do verbo. E, ainda, concluímos que a premissa inicial de que "as ordens relativas de pronomes fracos e clíticos nos domínios negativos, comparadas aos domínios afirmativos, além de confirmar a natureza clítica da palavra 'ñ̃o' em português, trazem indícios e pistas importantes sobre a história gramatical da língua" é verdadeira.

\section{Notas}

* O trabalho que deu origem a este artigo foi apresentado ao curso de Doutorado em Lingüística, Instituto de Estudos da Linguagem, Universidade Estadual de Campinas, em 2006, para o exame de qualificação na área de sintaxe. O texto original para o exame de qualificação - A negação sentencial no português: uma visão diacrônica - contou com a orientação da Profa. Dra. Sônia Maria Lazzarini Cyrino (UNICAMP), e teve como membros da bancada examinadora as Profas. Dra. Maria Aparecida Torres Moraes (USP) e Dra. Maria Clara Paixão de Sousa (UNICAMP/ USP). Nessa empreita também contei com a leitura e importante contribuição da Profa. Dra. Ana Maria Martins (Universidade de Lisboa), na ocasião de meu estágio de doutoramento na Universidade Clássica de Lisboa, em 2006. Agradeço a todos pelas conversas produtivas e indicações que contribuíram nesta minha singela exploração e reflexão sobre a sintaxe da negação sentencial. E, certamente, dos deslizes e tropeços assumo a sua autoria.

Agradeço, outrossim, pelo apoio financeiro da Fundação de Amparo à Pesquisa do Estado de São Paulo (FAPESP, Doutorado 04/01557-0). 
${ }^{1}$ A teoria da gramática gerativa, adotando a representação X', além das projeções lexicais propõe que o 'dicionário mental' contém também projeções funcionais. Os núcleos funcionais têm função eminentemente gramatical. A flexão verbal constitui uma categoria funcional que a teoria convencionou chamar de IP (sigla vinda do inglês para 'sintagma flexional' - inflectional phrase). INFL $^{\circ}$ ou $\mathrm{I}^{\circ}$ é o núcleo do sintagma da flexão verbal, IP. As análises dentro da perspectiva atual da teoria optaram por dividir o nódulo da flexão verbal - IP - em tempo e concordância - respectivamente TP (tense phrase) e AgrP (agreement phrase). A relação de dominância entre essas categorias foi bastante discutida (ex: CHOMSKY, 1989; POLLOCK, 1989; LAKA, 1990; OUHALLA, 1990; IATRIDOU, 1990; BELLETTI, 1990; ZANUTTINI, 1991, entre muitos outros trabalhos). Não são raras as análises que propõem duas projeções de $\mathrm{Agr}^{\circ}$ : uma para o sujeito (AgrSP), outra para o objeto (AgrOP). Além da flexão verbal, outra projeção funcional essencial na teoria é a projeção que traduz a subordinação - CP (complementizer phrase).

${ }^{2}$ A teoria da gramática gerativa, adotando a representação $X$ ', divide os constituintes sintáticos entre elementos nucleares $\left(\mathrm{X}^{\circ}\right)$ e/ou sintagmáticos (XP).

${ }^{3}$ A teoria da gramatical, dentro do modelo Minimalista proposto por Chomsky (1995) e também nos modelos anteriores de Lectures on Government and Binding - GB (Regência e Ligação), divide a gramática em 3 módulos principais: Sintaxe, Fonologia e Semântica. No quadro minimalista (CHOMSKY, 1995; 2001), tais módulos são representados por níveis requeridos pela necessidade conceitual, ou seja, aqueles que interagem com os sistemas de desempenho: A-P (Sistema Articulatório-Perceptual) e C-I (Sistema Conceptual-Intencional). Os níveis lingüísticos que interagem com A-P e C-I são, respectivamente, PF (Forma Fonológica, do inglês, Phonological Form) e LF (Forma Lógica, do inglês, Logical Form). Em GB, além dos níveis PF e LF, existem dois níveis de derivação na sintaxe: Deep Structure - DS; e Superficial Structure - SS. Tais níveis foram abolidos da estrutura no minimalismo por princípios de economia, e, para derivar os fenômenos lingüísticos que eram explicados através de operações que se davam nesses dois níveis, supõe-se que a faculdade da linguagem é constituída por um léxico e por um sistema computacional.

${ }^{4}$ Parênteses indicam opcionalidade.

${ }^{5}$ Orações raízes introduzidas por elementos que não são operadores preclisadores, como sujeito, sintagmas preposicionados, orações antepostas, conjunção coordenativa ' $e$ ', 'mas' $e$ 'ou', ou seja, elementos que constituem contextos de variação ênclise vs. próclise nos domínios afirmativos, nos textos antigos e clássicos. 
${ }^{6}$ Os estudos atuais, voltam a propor uma entrada lexical clítica para a negação por: 1) constatarem a sobrevivência da interpolação de 'não' no português contemporâneo (ex: "O João pediu que lhe não acordasse"). 2) Por causa da sua obrigatoriedade de acompanhar o movimento do verbo para $\mathrm{C}^{\circ}$ (ex: "O que não tem o João lido às crianças?" $v s$ “* O que tem o João não lido às crianças?”). 3 ) O fato de só os pronomes clíticos poderem se interpor entre 'não' e 'verbo' (Ex: “*O João não já lê esses livros.”). (MATEUS et al. 2003, p.866 e 867).

${ }^{7}$ Apesar de Diogo do Couto ser um autor da época clássica, produz algumas interpolações do tipo arcaico (C-cl-XnegV), porém são marginais em relação a estrutura sem a interpolação de elementos diferentes de 'não' (C-X-clnegV).

${ }^{8}$ De acordo com Galves (2004), Galves, Namiuti e Paixão de Sousa (2006), este período que vai desde o século 15 até início do século 18 corresponde a uma fase gramatical intermediária designada, pelas autoras, de português médio. Entretanto, a tradição filológica chama de português médio um curto período entre o português antigo e o clássico, que não ultrapassa a segunda metade do século 15 (CARDEIRA, 2005; CASTRO, 2006).

${ }^{9}$ Martins (2000, p. 202) traz a idéia de Rooryck (1994) sobre a natureza do sistema de traços, segundo a qual os traços devem estar associados a um valor de três possíveis: especificado (+), invariável e subspecificado (0), variável e subspecificado $(\alpha)$. O valor 0 marca a ausência de qualquer propriedade relacionada com o traço em questão. Isso significa dizer que um elemento com [traço-neg 0] é simplesmente incapaz de fazer qualquer operação relacionada com uma expressão de sentido negativo (é opaco, emprestando o termo da fonologia). Já o valor a é sensível ao contexto, dado um ambiente adequado, ele se harmoniza (podemos dizer que é transparente).

${ }^{10}$ Pollock (1989), por exemplo, propõe que a estrutura profunda (DS, Deep Structure) da oração negativa é a que tem NEGP intercalado entre TP e AgrP (na análise de Pollock TP domina AgrP). Os princípios básicos para que essa DS resulte na SS (Superficial Structure) de cada uma das línguas são derivados da Teoria de Quantificação e da Teoria Temática $(\theta)$. No entanto, as análises em que NegP não está acima de INFL não dão conta e causam complicação para derivar alguns fenômenos sintáticos envolvendo o marcador de negação sentencial, como o licenciamento de IP nulo em algumas línguas (cf. LAKA, 1990; MIOTO, 1992).

${ }^{11}$ Para uma versão mais atual da teoria (CHOMSKY, 2001 e 2004), o movimento do sujeito para Spec/TP não é necessário para a atribuição do caso nominativo, este é atribuído por $\mathrm{T}^{\circ}$ ao sujeito em Spec de vP pela operação 'Agree'.

${ }^{12}$ Nas línguas românicas não se atesta a elipse de VP como no inglês, ou seja, não há elipse licenciada por INFL. A idéia é que o que se tem é elipse ou apagamento de 
TP, portanto não será INFL o licenciador da elipse - fenômeno designado stripping (despojamento). Segundo Hankamer and Sag (1976, p. 409), stripping é a regra que apaga em uma oração (clause) tudo que é idêntico a partes correspondentes na oração precedente (the correlate), exceto um constituinte (the remnant).

${ }^{13}$ Spell-out é a operação responsável pela interpretação fonética da estrutura da oração. A regra de spell-out separa a estrutura relevante para a interpretação fonética da estrutura que pertence à interpretação semântica e envia cada uma das estruturas para a interface apropriada. Se spell-out se aplica antes de os traços fortes serem checados, esses traços não checados causam o fracasso da derivação em PF. Posto isso, operações de movimento visível devem ocorrer antes de spell-out. Entretanto, se uma operação de movimento que ocorre antes de spell-out checar apenas traços fracos, a derivação (se convergente) é bloqueada por Procrastinar. Se não há traços fortes envolvidos, a checagem de traços fracos deve proceder através de movimentos na 'sintaxe não visível', depois de spell-out, em LF (Forma Lógica, do inglês Logical Form).

${ }^{14}$ Gostaria de chamar a atenção para o fato de que nessa derivação é necessário supor que Spec de AgrS não pode ser projetado quando $\sum-\mathrm{Neg}^{\circ}$ é preenchido, do contrário não se pode capturar o fato da adjacência obrigatória 'neg-(cl)- V'.

${ }^{15}$ Martins (em conversa) lembra que, nas estruturas de marcação excepcional de caso (ECM - Exceptional Case Marking), não há o bloqueio da subida do clítico pela negação.

"O Pedro disse-me que o médico o mandou não beber vinho".

A meu ver, isso não invalida a generalização de Mioto por um motivo: o clítico acusativo 'o' não é um argumento interno de 'beber', mas o sujeito de 'beber'. "O Pedro disse que o médico mandou o João não beber vinho". O caso acusativo para esse sujeito não é atribuído pelo verbo 'beber', mas pelo verbo 'mandou'. Portanto, 'o' não faz parte da morfologia de 'não-beber', mas de 'mandou'.

${ }^{16}$ A intervenção de elementos entre os verbos de um predicado complexo também é encontrada em textos antigos. Exemplo abaixo retirado do texto de Francisco de Holanda (1517-1584) - Da Pintura Antiga.

"Nem dezia mal o que um duque bem o podia elle fazer ou um conde, mas um pintor excelente, que só Deos o podia fazer no tempo que elle quisesse, pola qual razão deixou de dar a morte a um que o mereciam."

${ }^{17}$ De acordo com Martins (1994) 'SIM', ao contrário de NÃO, não é a expressão dos traços de polaridade oposta ao $\mathrm{NEG}^{\circ}$, ou seja $\mathrm{AF}^{\circ}$. Portanto, NÃO não tem um comportamento paralelo à SIM em português. Como vimos, o conteúdo lexical 
presente em $\Sigma-\mathrm{Af}^{\circ}$ em português é o próprio verbo. Fato que explica o padrão da resposta afirmativa poder ser o verbo, e ainda fortalece a hipótese de que 'NÃO' é a expressão de $\Sigma-\mathrm{Neg}^{\circ}$.

${ }^{18}$ Nesse caso, podemos supor uma lógica na ordenação dos morfemas 'verbais' de acordo com a recursividade de cada língua: Sabemos que no japonês a ordem dos morfemas verbais é 'verbo+neg +(tempo passado)', com o verbo e o complemento à esquerda sob o escopo da negação (língua SOV); nas línguas SVO, como o português, temos ordem contrária "neg-V", com o verbo e o complemento à direita sob o escopo da negação.

${ }^{19}$ No entanto, é importante ressaltar que a negação, ao contrário do determinante, é uma palavra funcional que corresponde a uma palavra prosódica no sentido de portar um acento independente. A respeito dos determinantes, preposições e pronomes clíticos, Vigário (1999, p. 257) diz que "none of these Fncs (funtional words) can be an element of a Phonological Phrase (f) by a change in the unmarked stress pattern of $f$, a possibility that is available at least for some stressed items such as the marker of sentence negation 'não"”. De acordo com Vigário (1999, p. 282287) também os complementadores podem portar um acento (de ênfase, por exemplo) e assim formar uma palavra prosódica independente.

20 "Diálogo da Viciosa Vergonha" (DVV), "Diálogo em Louvor da Nossa Linguagem" (DLNL) e "Gramática da Língua Portuguesa" (GLP).

${ }^{21}$ O problema está na concepção do que é um clítico e de quais são os processos fonológicos que envolvem os clíticos. Uma definição bastante assumida para os clíticos é a de Spencer (1991), para quem os clíticos são elementos com certas propriedades de palavras plenas, mas sem acento próprio, dependentes de acentos de outras palavras, comportando-se desse modo como afixos. No entanto, ele ressalva que os processos fonológicos que envolvem os clíticos não são os mesmos que os afixos: Enquanto os afixos se aglutinam a palavras específicas, os clíticos se apóiam a qualquer palavra de acento forte, apesar de haver também clíticos que se comportam mais como afixos fixando-se a palavras específicas.

${ }^{22}$ Os exemplos negativos são de Cyrino. Acrescentei a contraparte afirmativa.

${ }^{23}$ De acordo com Mattos (1994), também Busquets (2006), nas línguas românicas não se atesta a elipse do $V P$ como no inglês, ou seja, não há elipse licenciada por INFL. A idéia é que o que se tem é elipse ou apagamento de TP, portanto não será INFL o licenciador da elipse - fenômeno designado de stripping (despojamento). (Falamos sobre esse assunto na nota 12). 
${ }^{24}$ Além das duas possibilidades do emprego dos artigos apresentadas, muitos autores consideram o clítico acusativo (o, a, os, as) um 'determinante'. Nesse caso não há a possibilidade da realização do nome (ex: “Comprei-o."). Esta idéia de que ' $o$ ', ' $a$ ', 'os, 'as' pertencem a uma só categoria com três possibilidades de realização está impressa também em João de Barros.

"A pequeno tem três officios. Serve per sy só de artigo feminino, e de relativo do mesmo gênero, e em composiçám das outras leteras. - De artigo como "a matéria bem feita apraz ao mestre". Serve de relativo per semelhante exemplo: "essa tua palmatória, se â eu tomar far-te-ey lembrar esta regra", e entam tem necessidade daquelle espírito que lhe vês encima pêra diferença dos outros officios. Em composiçám: "o temor de Deos faz bõa conciencia". (João de Barros, GLP)

${ }^{25} \mathrm{Se}$ assim for, a razão de a negação condicionar categoricamente a próclise verbal do pronome clítico não deve derivar do seu caráter de 'operador', no sentido dos demais advérbios e operadores que condicionam a próclise, mas sim do fato de que os clíticos devam ocorrer amalgamados em português, e, sendo 'neg' sempre pré-verbal, a próclise do pronome é derivada, pois o clítico negativo atrai o pronome para ficar alinhado de maneira adjacente a ele. A ordem 'cl-neg-V' não poderá ser derivada em nenhum contexto no PE por conta de que esse elemento não pode receber o acento secundário inicial característico da palavra fonológica no PE (de acordo com ABAURRE e GALVES, 1998, também d'ANDRADE e LAKS, 1992, o PE tem a tendência de acentuar o início de palavra). Como os clíticos pronominais não podem portar tal acento, a ordem padrão dos 'morfemas verbais no $\mathrm{PE}$ atual é 'neg-cl-V', já que nos contextos negativos o clítico deve se mover para dentro do complexo verbal e, portanto, fazer parte do domínio da palavra de ação.

${ }^{26}$ Remeto à Costa e Martins (2004).

27 "Morphological Merger, proposed first in Marantz 1984, was originally a principle of well-formedness between levels of representation in syntax. In: MARANTZ, 1988, p. 261 Merger was generalized as follows: [...] // At any level of syntactic analysis (d-structure, s-structure, phonological structure), a relation between $\mathrm{X}$ and $\mathrm{Y}$ may be replaced by (expressed by) the affixation of the lexical head of $\mathrm{X}$ to the lexical head of Y. // What Merger does is essentially 'trade' or 'exchange' a structural relation between two elements at one level of representation for a different structural relation at a subsequent level.// Merger has different consequences depending upon the level of representation it occurs at. Where Merger applies in syntax proper it is the equivalent of Head Movement, adjoining a zero-level projection to a governing zero-level projection (BAKER, 1988). Syntactic Lowering may be a type of Merger as well, presumably occuring after syntax proper but 
before Vocabulary Insertion. See Bobaljik, 1994.” (NOYER, 2004, p.10)

${ }^{28}$ De acordo com Kayne (1991), também Raposo (2000), os clíticos são adjungidos à esquerda do núcleo mais alto alcançado pelo movimento do verbo.

${ }^{29} \mathrm{CL}, \mathrm{L}$ I' = essa interação morfológica se traduz em: "o clítico deve se alinhar a esquerda de I" ".

${ }^{30}$ A restrição Non-Initial CL, $1^{\circ} \mathrm{X}$ ' diz que o domínio em que o clítico não pode ser inicial é o $1^{\circ} \mathrm{X}^{\prime}$, ou seja, o pronome clítico não pode se alinhar à esquerda do Primeiro X' da oração. Portanto, na análise de Galves e Sândalo, quando I' é o $1^{\circ}$ $X^{\prime}$ da oração, a ênclise é derivada por violar a restrição Non-Initial e por esta ser mais importante no ranking que edgmost.

${ }^{31}$ A diferença do PE para o PM (português médio, século 15 ao 17), segundo Galves e Sândalo, está no domínio em que Non-Initial se aplica. Em PE, o domínio no qual essa restrição se aplica é claramente o primeiro X'. Resta-nos saber qual o domínio em que Non-Initial se aplica nos períodos gramaticais na história do português. Galves e Sândalo não entram neste mérito, porém, as considerações e pistas deste domínio foram tratadas por Namiuti (2008).

${ }^{32}$ Segundo Costa (2001) quando dois complementos do verbo são antepostos a ordem entre eles não é fixa:

1) Aos alunos, esses livros, o Paulo deu-lhos ontem...

2) Esses livros, aos alunos, o Paulo deu-lhos ontem...

Se assumimos que o sujeito é deslocado à esquerda, então esperaríamos a mesma flexibilidade. Tal não acontece:

3) Esse bolo o Paulo comeu-o.

4) *O Paulo, esse bolo comeu-o.

${ }^{33} \mathrm{~A}$ autora propõe que o sujeito pré-verbal em PE ocupa uma posição de adjunção à IP, como os tópicos. E a ênclise é derivada desse fato, seguindo a lei de ToblerMussafia.

${ }^{34}$ Ao contrário do que foi proposto nos trabalhos de Martins, acredito que Spec de $\Sigma$ Pé incompatível com a ênclise. As evidências para isso estão no português clássico onde temos a predominância da próclise nas sentenças SV e o surgimento da possibilidade de interpolação da negação nessas construções (ver trabahos de GALVES, 2003; GALVES; PAIXÃO DE SOUSA, 2005; GALVES, PAIXÃO DE SOUSA E NAMIUTI, 2006).

${ }^{35}$ A explicação para esta posição e não outra deve estar ligada ao fato de a negação ter escopo naturalmente ao constituinte que a segue, fato que deve ser derivado da recursividade da língua que se dá da esquerda para a direita. 
${ }^{36}$ Três são as maneiras de explicar esta ordem dos núcleos: 1) pode ser explicada pela fonologia - por conta da acentuação secundária do PE, como comentamos na nota $25 ; 2$ ) pode ter explicação na recursividade - o clítico tem que estar à direita do não para que a negação tenha escopo sobre ele; e 3) pela 'lei' de que os clíticos devem ocorrer amalgamados, com a negação isso ocorre quando estão dentro da mesma fronteira morfológica.

37 "Partícula negativa" talvez traduzisse melhor esta idéia, mas como Mioto já propôs "clítico negativo" para a relação morfológica dependente de 'neg' e 'verbo' manteremos essa nomenclatura.

\section{Referências}

ABAURRE, M. B.; GALVES, C. M. C. As diferenças rítmicas entre o português europeu e o português brasileiro: uma abordagem otimalista e minimalista. DELTA I, São Paulo, v. 14, n. 2, 1998.

ANDERSON, Stephen R. Towards an optimal account of second-position phenomenon. In: DEKKERS, Joost; LEEUW, Frank van der; WEIJER, Jeroen van de (Ed.). Optimality Theory: phonology, syntax, and acquisition. Oxford University Press, 2000.

ANDRADE, E. d'; LAKS, B. Na crista da onda: o acento de palavra em português. Actas do $7^{\circ}$ Encontro da Associação Portuguesa de Lingüística. Lisboa, 1992.

BAKER, M. Incorporation. A theory of grammatical fuction changing. Chicago. University of Chicago Press, 1988.

BARBOSA, Pilar. Null Subjects. Doctoral Dissertation, MIT, 1995.

BARBOSA, P. Clitics: a window into the Null Subject Property. COSTA, João (Org.). Portuguese Syntax. New York: Oxford University Press, 2000.

BELLETTI, A. Generalized Verb Moviment: Aspects of Verb Syntax. MS, University de Genève, 1990.

BENINCÀ, P.; G. CINQUE. Su Alcune Differenze fra Enclisi e Proclisi. Omagio a Gianfranco Folena, Pádua, Programma, p. 2313-2326, 1993.

BUSQUETS, J. Stripping vs. VP ellipsis in Catalan: What is deleted and when? International Journal of Latin and Romance Linguistics, v. 18, n.2, 2006.

CARDEIRA, E. Entre o português antigo e o português clássico. Imprensa Nacional Casa da Moeda, 2005.

CASTRO, I. Introdução à História do Português. Lisboa: Edições Colibri, 2006. 
CHOMSKY, N. Syntactic Sytructures . Mouton. The Hague. 1957.

CHOMSKY, N. Remarks on nominalization. JACOBS, R.; ROSENBAUM, P. (Org.). Reedings in English transformational grammar. Waltham, MA, Ginn, 1970.

CHOMSKY, N. Some notes on economy of derivation and representation. In: FREIDIN, Robert (Ed.). Principles and parameters in comparative grammar. Cambrigde, Massachusetts: The MIT Press, 1989.

CHOMSKY, N. Minimalist program for linguistic inquiry. In: HALLE, K.; KEYSER, J. (Ed.). View from the building 20. Cambridge (MA): MIT Press, 1993.

CHOMSKY, N. The Minimalist Program. Cambridge (MA): MIT Press, 1995.

CHOMSKY, N. Derivation by Phase. In Ken Hale: A life in language. Kenstowing, Michael (ed). Cambridge (MA): MIT Press, 2001.

CHOMSKY, N. Sytuctures and beyond - the cartography of syntatic structures.v. 3. Oxford/New York: Oxford University Press, 2004.

COSTA, J. Word Order and Constraint Interaction: A constraint based approach. PhD Dissertation, LeidenUniversity, 1998.

COSTA, J. Word Order and Configurationality in European Portuguese. In: COSTA, J. (Ed.). Portuguese Syntax - New comparative studies. Oxford: Oxford University Press, 1999.

COSTA, J. Spec, IP ou Deslocado? Prós E Contras Das Duas Análises Dos Sujeitos Pré-Verbais. DELTA I, São Paulo, v.17, n. 2, 2001.

COSTA, J. Subjects in Spec, vP: Locaity and Agree. In: CASTRO, Ana; FERREIRA, Marcelo; SALANOVA, Andrés Pablo (Org.). Collected papers on Romance Syntax. MIT working papers. v. 47, p. 41-55, 2004.

COSTA, João; DUARTE, Inês. Preverbal subjects in null subjects languages are not necessarily dislocated. Journal of Portuguese Linguistic, 1, p. 159-175, 2002.

COSTA, João; MARTINS, Ana Maria What is strong functional head?. Lisbon Whorkshop on Alternative Views on the Functional Domain, 2004.

CYRINO, Sônia M. L. A acentuação gráfica em João de Barros e elementos nulos no SN. Estudos Lingüísticos e literários, n.19, p. 189-196, 1997.

DAHL, O. Typology of Sentence Negation. Linguistics, v. 17, p. 79-106, 1979.

EMBICK, D. E Noyer, R. Movement Operations After Syntax. Linguistic Inquiry 32: 4, p. 555-595, 2001. 
FROTA, Sónia. Is Focus a Phonological Category in Portuguese? In: ACKEMA, P.; SCHOORLEMMER, M. (Org.). Proceedings of ConSole I. The Hague: Holland Academic Graphics, p. 69-86, 1994.

GALVES, Charlotte. Clitic in European Portuguese. Evidence for a nonhomogeneous theory of clitics. Atas do workshop sobre o Português. Associação Portuguesa de Lingüística, Lisboa, 1992.

GALVES, Charlotte, Colocação de clíticos e mudança gramatical no português europeu. Comunicação no $12^{\circ}$ Encontro da Associação Portuguesa de Linguística, Braga, Portugal. 1996.

GALVES, Charlotte. Ensaios sobre as Gramáticas do Português. Campinas: Ed. UNICAMP, 2001.

GALVES, C. M. C. Syntax and Style: clitic-placement in Padre Antonio Vieira. Santa Barbara Portuguese Studies, Santa Barbara, v. 6, p. 387-403, 2002.

GALVES, Charlotte. Clitic Placement in the History of Portuguese and the Syntax Phonology Interface. XXVII Penn Linguistics Colloquium. 2003.

GALVES, C. Padrões Rítmicos, Fixação de Parâmetros e Mudança LingüísticaFase II. UNICAMP, Campinas. (Projeto de pesquisa FAPESP), 2004.

GALVES, C. M. C.; DOBROVIE-SORIN, C. Proclisis, enclisis and head-to-head merge. Bucharest Working Papers in Linguistics, Bucharest, v. II, n. 1, p. 35-50, 2000.

GALVES, Charlotte; PAIXÃO DE SOUSA, Maria Clara. Clitic placement and the position of subjects in the history of European Portuguese. In: GEERTS, T.; GINNEKEN, I. Van; JACOBS, H. (Org.). Languages and Linguistic Theory, Selected papers from 'Going Romance' 2003, John Benjamins, 2005. p. 93-107.

GALVES, Charlotte; NAMIUTI, Cristiane; PAIXÃO DE SOUSA, Maria Clara. Novas perspectivas para antigas questões: revisitando a periodização da língua portuguesa. Grammatische Structuren des Europäischen Portugiesisch. Annette Endruschat / Rolf Kemmler / Bárbara Schäfer-PrieB (Hrsg). Turbigen: Calapinus Verlag, p. 45-75, 2006.

GALVES, Charlotte; SÂNDALO, Maria Filomena. Clitic placement in Modern and Classical European Portuguese. In: CASTRO, Ana; FERREIRA, Marcelo; SALANOVA, Andrés Pablo (Org.). Collected papers on Romance Syntax. MIT working papers, v. 47, 2004.

HALLE, M.; MARANTZ, M. Distributed morohologie and the pieces of inflection. View from the Building 20: Essays in Linguistics in honor of Sylvain Bromberger. HALLE, K.; KEYSER. J. (Ed.). Cambridge, MA: MIT Press, 1993. 
HANKAMER, J.; SAG, I. Deep and Surface Anaphora. Linguistic Inquiry, v. 7, n. 3, p. 391-426, 1976.

IATRIDOU, Sabine. About Agr(P). Linguistic Inquiry, v. 21, p. 551-577, 1990.

KAINE, Richard. Romance clitics, verb moviment and PRO. Linguistic Inquiry, v. 22, p. 647-686, 1991.

LAKA Mugarza, Miren Itziar. Negation in Syntax: On the Nature of Functional Categories and Projections. Ph. D. Dissertation. Cambridge, Massachussets: MIT, 1990.

LOBECK, Anne. Ellipsis. Funcional Heads, Licensing and Identification. Oxford: Oxford University Press, 1995.

MARTINS, Ana Maria. Clíticos na história do português. Tese de Doutoramento, Universidade de Lisboa, 1994.

MARTINS, Ana Maria. Mudança Sintática. Clíticos, negação e um pouquinho de Scrambling. Estudos Lingüísticos e Literários, n. 19, Salvador: Programa de Pós Graduação da Universidade Federal da Bahia, 1997.

MARTINS, Ana Maria. Polarity Items in Romance: Underspecification and Lexical Change. In: SUSAN, Pintzuk; TSOULAS, George; WARNES, Anthony (Org.). Diachronic Syntax: Models and Mechanisms. Oxford: Oxford University Press, 2000.

MARTINS, Ana Maria. Deficient pronouns and linguistic changes in Portuguese and Spanish. SCHROTEN, J. (Ed.). Romance Language and Linguistic Theary 2001: Selected Papers from 'Going Romance’2001. Amsterdam and Philadelphia: John Benjamins, 2003a.

MARTINS, Ana Maria. From Unity to Diversity in Romance Syntax. Portuguese and Spanish. BRAUNMÜLLER, Kurt; FERRARESI, Gisella (Ed.). Aspects of Multilingualism in European Language History. v. 2. Amsterdam / Philadelphia: University of Hamburg. John Bejanmins Publishing Company. 2003b.

MARTINS, Ana Maria. Clitic Placement, VP-Ellipsis and Scrambling in Romance. BATILBORI, Montse; HERMANZ, Maria Lhuïsa; PICALLO, Carme; ROCA, F. (Ed.). Gramaticalization and Parametric Variation. Oxford: Oxford University Press, 2005.

MATEUS, M. H. M.; BRITO, A. M.; DUARTE, I.; FARIA, I. H. Gramatica da Lingua Portuguesa. Lisboa: Caminho, 2003.

MATOS, Gabriela Ardisson. A Distribuição de Despojamento. DUARTE, Inês; LEIRIA, Isabel (Org.). Congresso Internacional sobre o Português. v. II. Lisboa: Edições Colibri, 1994. 
MIOTO, Carlos. Negação Sentencial no Português Brasileiro e Teoria da Gramática. Tese (Doutorado em Lingüística) - UNICAMP, Campinas, 1992.

MUIDINE, Soraia Aboo. Os pronomes i e en(de) no português dos séculos XIII ao XVI. Dissertação de Mestrado, Lisboa, 2000.

NAMIUTI, Cristiane. Interpolação, colocação de clíticos e mudança gramatical na história do português europeu. Tese (doutorado). UNICAMP, Campinas, 2008.

NOYER, R. Distributed Morphology. Disponível em: <http://www.ling.upenn.edu/ $\sim$ rnoyer/dm/>. Acesso em: 2004.

OUHALLA, J. Sentential negation, Relativized Minimality, and the aspectual status of auxiliaries. The Linguistic Review, v. 7, p. 183-231, 1990.

POLLOCK, J. I. Verb Movement, UG and the Structure of IP. Linguistic Inquiry 20, p. 365-424, 1989.

RAPOSO, Eduardo P. Clitic Positions and Verb Movement. In: COSTA, J. (Ed.). Portuguese Syntax: New Comparative Studies, Oxford Studies in Comparative Syntax. Oxford: Oxford University Press, 2000. p. 266-297.

SANTOS, Lucas. O desempenho do não como prefixo no português brasileiro contemporâneo. In: COSTA, Sônia Bastos; MACHADO FILHO, Américo Venâncio Lopes (Org.). Do Português Arcaico ao Português Brasileiro. Edulfba, 2005.

VALLDUVÍ, E. The informational component. Garland Publishing. Nova York I Londres. (Resumindo a seção 7.3 - sobre a negação), 1992.

VIGÁRIO, Marina. On the Prosodic Status of Stressless Function Words in European Portuguese. HALL, T. Alan; KLEINHENZ, Ursula (Ed.). Current Issues in Linguistic Theory: Studies on the Phonological Word. John Benjamins Publishing Company. Amsterdam/Philadelphia, 1999. p 255-295.

VIGÁRIO, Marina. Quando meia palavra basta: Apagamento de palavras fonológicas em estruturas coordenadas. In: CASTRI, I.; DUARTE, I. (Ed.). Razoes e Emoções. Miscelânia de estudos em homenagem a Maria Helena Mira Mateus. v. II. Lisboa: Colibri, 2003. p 415-435.

ZANUTTINI, Rafaella. Syntatic Properties of Sentential Negation. A Comparative Study of Romance Languages. PhD Thesis. University of Pennsylvania, 1991.

ZANUTTINI, Rafaella. Re-examining Negative Clauses. In: CINQUE, G.; POLLOCK, J.-Y.; RIZZI, L.; ZANUTTINI, R. (Ed.). Paths Towards Universal Grammar: Studies in honor of Richard Kayne. Washington, D. C.: Georgetown University Press, 1994. p. 427-451. 